\title{
Surfactants in cloud droplet activation: mixed organic-inorganic particles
}

\author{
N. L. Prisle ${ }^{1,4}$, T. Raatikainen ${ }^{2}$, A. Laaksonen ${ }^{2,3}$, and M. Bilde ${ }^{4}$ \\ ${ }^{1}$ University of Helsinki, Department of Physics, P.O. Box 48, 00014, University of Helsinki, Finland \\ ${ }^{2}$ Finnish Meteorological Institute, Erik Palmenin Aukio 1, 00101, Helsinki, Finland \\ ${ }^{3}$ University of Kuopio, Department of Physics, P.O. Box 1627, 70211, Kuopio, Finland \\ ${ }^{4}$ University of Copenhagen, Department of Chemistry, Universitetsparken 5, 2100, Copenhagen, Denmark
}

Received: 13 October 2009 - Published in Atmos. Chem. Phys. Discuss.: 18 November 2009

Revised: 27 May 2010 - Accepted: 4 June 2010 - Published: 29 June 2010

\begin{abstract}
Organic compounds with surfactant properties are commonly found in atmospheric aerosol particles. Surface activity can significantly influence the cloud droplet forming ability of these particles. We have studied the cloud droplet formation by two-component particles comprising one of the organic surfactants sodium octanoate, sodium decanoate, sodium dodecanoate, and sodium dodecyl sulfate, mixed with sodium chloride. Critical supersaturations were measured with a static diffusion cloud condensation nucleus counter (Wyoming CCNC-100B). Results were modeled from Köhler theory applying three different representations of surfactant properties in terms of surfactant surface partitioning and reduced droplet surface tension. We here confirm previous results for single-component organic surfactant particles, that experimental critical supersaturations are greatly underpredicted, if reduced surface tension is used while ignoring the effects of surface partitioning in droplets. Furthermore, disregarding surfactant properties by ignoring surface partitioning and assuming the constant surface tension of pure water can also lead to significant underpredictions of experimental critical supersaturations. For the mixed particles comprising less than $50 \%$ by mass of surfactant, this approach however still provides a good description of the observed droplet activation. A comprehensive account for surfactant properties, including both surface tension reduction and effects of surface partitioning in activating droplets, generally predicts experimental critical supersaturations well.
\end{abstract}

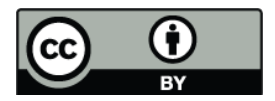

Correspondence to: N. L. Prisle (nonne.prisle@helsinki.fi)

\section{Introduction}

The influence of atmospheric aerosol particles on cloud formation and properties constitutes the single largest uncertainty in assessing anthropogenic climate forcing (IPCC, 2007). Cloud droplets form when water vapor condenses onto particle surfaces. In the process, particle constituents may dissolve into the aqueous phase and form solution droplets. The ability of particles to act as cloud condensation nuclei $(\mathrm{CCN})$ therefore depends on chemical composition, as well as size. Surface active molecules (surfactants) concentrate in the surface and can reduce the surface tension of an aqueous solution. Reduced surface tension, compared to that of pure water, has been demonstrated in bulk samples of atmospheric cloud and fog water (Facchini et al., 1999, 2000) and in aqueous extracts of collected atmospheric aerosol samples from a wide variety of sources and environments, including biomass (Asa-Awuku and Sullivan, 2008) and coal burning (Oros and Simoneit, 2000), and marine (Mochida et al., 2002), rural (Kiss et al., 2005), and polluted environments (Dinar and Taraniuk, 2006). The goal of this work is to advance the fundamental understanding of the role of surfactants in cloud microphysics, which is essential for consistent representations of aerosol effects in atmospheric models.

Fatty acids and their salts constitute an important class of atmospheric surfactants and have been identified in aerosol samples from both marine (Mochida et al., 2003), urban (Yassaa et al., 2001), and continental (Cheng et al., 2004) environments. We have previously addressed the cloud droplet formation of single-component particles comprising a series of saturated fatty acid sodium salts and demonstrated

Published by Copernicus Publications on behalf of the European Geosciences Union. 
the importance of a comprehensive account for surfactant properties in thermodynamic model predictions (Prisle et al., 2008). Atmospheric particles are however generally mixtures of both organic and inorganic species (Murphy et al., 2006). In this work, we therefore proceed by investigating two-component particles comprising organic surfactants mixed with sodium chloride $(\mathrm{NaCl})$. These particles can be regarded as simple model systems for marine aerosols (O'Dowd et al., 2004).

We compare experimental observations of cloud droplet formation by mixed surfactant- $\mathrm{NaCl}$ particles to thermodynamic model predictions using different representations of surfactant properties in activating droplets. Specifically, we have studied the sodium salts of n-octanoic (caprylic), ndecanoic (capric) and n-dodecanoic (lauric) acid. In addition, we included sodium dodecyl sulfate (SDS), which is a strong industrial surfactant with well-quantified properties. SDS is not found in the atmosphere but has previously been targeted as a model compound for water-soluble atmospheric surfactants in cloud droplet formation studies of both singlecomponent particles and mixed particles with $\mathrm{NaCl}$ ( $\mathrm{Li}$ et al., 1998; Rood and Williams, 2001; Sorjamaa et al., 2004).

The fatty acid salts (FAS) and SDS are amphiphiles. Each molecular structure is characterized by a polar head-group (the $-\mathrm{COO}^{-}$or $-\mathrm{OSO}_{3}^{-}$functional groups) and a non-polar hydrocarbon tail (the unbranched $-\left(\mathrm{CH}_{2}\right)_{\mathrm{n}} \mathrm{CH}_{3}, \mathrm{n}=6,8,10$, chain). To reduce destabilizing interactions with the polar water molecules in the aqueous phase, the surfactant molecules preferentially accumulate at the air-water interface, with the hydrophilic ends dissolved in the aqueous solution and the hydrophobic tails pointing outwards to the air. This is the origin of their surface activity.

\section{Experimental}

We have measured the critical supersaturation as a function of dry particle diameter for two-component laboratorygenerated particles comprising organic surfactant (SFT) and sodium chloride $(\mathrm{NaCl})$ in different relative amounts. Particle compositions included one of the surfactants sodium octanoate $\left(\mathrm{CH}_{3}\left(\mathrm{CH}_{2}\right)_{6} \mathrm{COONa}\right.$; $\left.\mathrm{C} 8 \mathrm{Na}\right)$, sodium decanoate $\left(\mathrm{CH}_{3}\left(\mathrm{CH}_{2}\right)_{8} \mathrm{COONa} ; \mathrm{C} 10 \mathrm{Na}\right)$, sodium dodecanoate $\left(\mathrm{CH}_{3}\left(\mathrm{CH}_{2}\right)_{10} \mathrm{COONa} ; \mathrm{C} 12 \mathrm{Na}\right)$, and sodium dodecyl sulfate $\left(\mathrm{CH}_{3}\left(\mathrm{CH}_{2}\right)_{10} \mathrm{OSO}_{3} \mathrm{Na}\right.$; SDS $)$, mixed with $\mathrm{NaCl}$. Chemicals were obtained at the highest purities available from commercial sources: sodium octanoate (Sigma, capillary GC, minimum 99\%), sodium decanoate (Fluka, purum. 98\%), sodium dodecanoate (Sigma, Sigma Grade 99-100\%), sodium dodecyl sulfate (Sigma, >99\%), and sodium chloride (RiedeldeHaën, $>99.8 \%$ ). Before use, all chemicals were baked overnight at moderate temperatures $\left(<80^{\circ} \mathrm{C}\right)$ to evaporate any volatile impurities.
Table 1. Weighed surfactant solute mass-fractions ( $\left.W_{p, \mathrm{SFT}}[\%]\right)$ in the atomizer solutions.

\begin{tabular}{ccccc}
\hline SFT & $\sim 20 \%$ & $\sim 50 \%$ & $\sim 80 \%$ & $\sim 95 \%$ \\
\hline C8 & 20 & 51 & 79 & 95 \\
C10 & 20 & 50 & 73 & 94 \\
C12 & 23 & 53 & 81 & 95 \\
SDS & 20 & 51 & 81 & - \\
\hline
\end{tabular}

\subsection{CCN measurements}

Critical supersaturations were measured with a static thermal-gradient diffusion-type cloud condensation nucleus counter (Wyoming CCNC-100B) (Snider et al., 2006). The experimental set-up and procedures employed are described in detail in previous work (Prisle et al., 2008, and references therein).

Particles were generated by atomization of aqueous solutions using a constant output atomizer (TSI-3076), operated in recirculation mode. The wet aerosol produced was subsequently dried by passing through a set of two silicagel containing diffusion-driers in series, followed by dilution with dry air. The relative humidity (RH) in the dry aerosol was typically $5-8 \%$, except during one measurement (for about $1.5 \mathrm{~h}$ ) where the RH increased to nearly $20 \%$. Atomizer solutions were prepared with de-ionized and purified water $(18.2 \mathrm{M} \Omega \mathrm{cm}$ resistivity, produced in a Milli-Q Plus Ultra Pure Water System). Total solute concentrations were $0.12-0.31 \mathrm{gL}^{-1}$. Compositions of the dried particles are assumed to reflect the weighed relative mass fractions of organic and inorganic solutes in the atomizer solutions. Studied particle compositions thus comprise each FAS in approximate mass fractions of 20,50, 80, and 95\%, and SDS in approximate mass fractions of 20,50 , and $80 \%$, relative to $\mathrm{NaCl}$. Exact weighed surfactant mass-fractions ( $\left.W_{p, \text { SFT }}[\%]\right)$ are given in Table 1.

From the dried polydisperse aerosol, a narrow electricalmobility particle size-fraction was selected with an electrostatic classifier (TSI-3080). The number concentration of activated particles $\left(\mathrm{CCN}\left[\mathrm{cm}^{-1}\right]\right)$ at selected water vapor supersaturations (SS [\%]) was then measured with the CCNC. The total particle number concentration $\left(\mathrm{CN}\left[\mathrm{cm}^{-1}\right]\right)$ was measured in parallel, using a condensation particle counter (TSI-3010). Particle electrical-mobility diameters $\left(D_{p}\right)$ were $25-140 \mathrm{~nm}$ and CCNC supersaturations were $0.2-2.0 \%$. Purified and dried high-pressure air was used in all experiments. Laboratory temperatures $(T)$ were kept constant at 296-297 K during the course of each experiment by a thermostat air-conditioning system. 


\subsubsection{CCNC calibration and data fitting}

The CCN experiments give the fraction of activated particles $(\mathrm{CCN} / \mathrm{CN})$ with a selected mobility diameter as a function of the supersaturation that the particles were exposed to. These data were fitted with a four-parameter sigmoidal function, $y=y_{0}+a /\left[1+\exp \left(-\left(x-x_{0}\right) / b\right)\right]$ (Prisle, 2006; Prisle et al., 2008). Including correction for multiply-charged particles simultaneously selected in the classifier, the experimental critical supersaturation $\left(S S_{c}^{\exp }[\%]\right)$ was then determined from the midpoint of the singly-charged particle activation step $\left(x_{0}\right)$ : the CCNC supersaturation was calibrated with a linear relation, obtained from measurements using monodisperse ammonium sulfate $\left(\left(\mathrm{NH}_{4}\right)_{2} \mathrm{SO}_{4}\right)$ and $\mathrm{NaCl}$ particles (Bilde and Svenningsson, 2004), such that $S S_{c}^{\exp }=0.6638 x_{0}-0.01168$. Error bars given for $S S_{c}^{\exp }$ depict $\pm 2 \tau$ (approximate 95\%-confidence intervals), where $\tau$ is the combined standard deviation from the sigmoidal fit to activated fractions and the linear supersaturation calibration (Prisle, 2006).

\section{Theory}

\subsection{Köhler theory}

Cloud droplet formation is described in Köhler theory (Köhler, 1936) by the equilibrium growth and activation of an aqueous solution droplet. The Köhler equation relates the equilibrium water vapor saturation ratio $(S)$ over a spherical solution droplet to its diameter $(d)$ :

$S \equiv \frac{p_{w}}{p_{w}^{0}}=a_{w} \exp \left(\frac{4 v_{w} \sigma}{R T d}\right)$

where $p_{w}$ is the equilibrium partial pressure of water over the solution droplet, $p_{w}^{0}$ is the saturation vapor pressure over a flat surface of pure water, $a_{w}$ is the droplet solution water activity, $v_{w}$ is the partial molar volume of water in the solution, $\sigma$ is the droplet surface tension, $R$ is the universal gas constant, and $T$ is the Kelvin temperature.

The water activity $\left(a_{w}\right)$ in Eq. (1) is equivalently called the Raoult term and describes how the equilibrium partial pressure of water over an aqueous solution is suppressed from the pure water saturation vapor pressure by dissolved solutes according to (the extended) Raoult's Law, $p_{w}=a_{w} p_{w}^{0}$. The exponential, or Kelvin, term of Eq. (1) accounts for the vapor pressure enhancement over a curved droplet surface by the Kelvin effect. A plot of water saturation ratio versus droplet diameter $(S-d)$ gives the Köhler curve for a growing droplet and its maximum defines the critical saturation ratio $\left(S_{c}\right)$ and corresponding critical droplet diameter $\left(d_{c}\right)$. Droplets that have been exposed to ambient water saturation ratios larger than their respective threshold values $\left(S \geq S_{c}\right)$, and thus surpassed their critical diameters $\left(d \geq d_{c}\right)$, are assumed to be activated cloud droplets that will continue to grow into fullsized cloud drops, only limited by the transport of water vapor to the droplet surface. Below, we equivalently refer to the water vapor supersaturation, $S S /[100 \%] \equiv S-1$, and analogously to the droplet critical supersaturations $\left(S S_{c}[\%]\right)$.

\subsection{Surface partitioning}

Surfactant molecules preferentially accumulate at the airwater interface of aqueous solutions. This generates a concentration gradient between the solution bulk (superscript $B$ in the following) and surface (superscript $S$ ) phases. The relative distribution of surfactant molecules between these distinct solution phases is here referred to as the surfactant (bulk-)surface partitioning: it can be thought of as governed by some equilibrium constant, $K \propto \partial \Gamma / \partial c^{B}$, where $\Gamma$ (the surface excess) is the number concentration of surfactant molecules per unit area in the surface, and $c^{B}$ is the concentration per unit volume in the solution bulkphase. Surface partitioning thus depends on the intrinsic propensity of surfactant molecules for the surface (from the value of $K$ ), as well as the relative dimensions of the solution bulk and surface phases, due to the implicit dependency of $\partial \Gamma / \partial c^{B}$ on surface area $(A)$ and bulk volume $(V)$. For spherical liquid droplets with diameters of $d=0.1,1$, and $10 \mu \mathrm{m}$, the surface-area-to-bulk-volume ratio $(A / V=6 / d)$ is 60,6 , and $0.6 \mu \mathrm{m}^{-1}$, respectively, and $A / V \rightarrow 0$ as $d \rightarrow \infty$ for bulk solutions with flat surfaces.

The small solution droplets involved in cloud droplet formation typically have sub-micrometer diameters, whereas the dimensions of bulk solutions characterized by conventional laboratory methods or collected in field samples are much larger. We here denote bulk aqueous solutions as "macroscopic", and activating droplets as "microscopic". The term "bulk" is generally used to designate the isotropic bulk phase within an aqueous solution and distinguish it from the anisotropic surface phase. A similar practice was used in our previous work (Prisle et al., 2008) and is also employed by Ruehl et al. (2010).

Due to surface partitioning, $A / V$ becomes a key factor in determining surfactant solution properties. Equilibrium water activity $\left(a_{w}\right)$ and surface tension $(\sigma)$ are expressed as functions of solution bulk-phase composition $\left(c^{B}\right)$. However, surface partitioning depletes the bulk phase of surfactant molecules and thereby decreases $c^{B}$. Given the same surfactant concentration per unit of total (superscript $T$ ) solution volume $\left(c^{T}\right)$, the larger $A / V$ of microscopic droplets causes a larger fraction of the total number $\left(n^{T}\right)$ of surfactant molecules in solution to partition to the surface $\left(n^{S}\right)$ and a smaller fraction to remain in the bulk phase $\left(n^{B}\right)$, compared to macroscopic solutions. The change in bulk-phase composition from the total surfactant concentration due to surface partitioning is negligible for macroscopic solutions $\left(c^{B} \sim c^{T}\right)$. In microscopic droplets, bulk-phase depletion of surfactant molecules can on the other hand be significant 
$\left(c^{B} \ll c^{T}\right)$. The importance of surface partitioning for changing microscopic solution properties, compared to macroscopic solutions of the same overall composition, has previously been noted by Seidl and Hanel (1983), Bianco and Marmur (1992), and Laaksonen (1993).

Surfactant surface partitioning in microscopic droplets potentially affects cloud droplet activation through both Raoult and Kelvin effects. A smaller surfactant bulk-phase concentration will be reflected in a larger water activity (a diminished water partial pressure suppression by the Raoult effect) and a larger surface tension (a diminished surface tension reduction). At a given droplet size, the latter thus leads to an amplified curvature enhancement of water vapor pressure by the Kelvin effect. A simple illustration of the effects of surface partitioning on surfactant bulk-phase concentration and surface tension in droplets of different sizes is presented in Appendix A.

\section{Thermodynamic model}

The details of our thermodynamic model have been described in previous work (Sorjamaa et al., 2004; Prisle et al., 2008, and references therein). Some modification have been made, compared to the original version; for completeness, the model structure, equations and assumptions are therefore reviewed here.

\subsection{Köhler calculations}

Model calculations determine critical supersaturations $\left(S S_{c}\right)$ for growing droplets formed on dry particles of known composition and diameter, by iterating the respective Köhler curve maxima from Eq. (1).

Dry particles are assumed to be spherical with (volumeequivalent) diameters $\left(D_{p}^{e}=D_{p}\right)$ corresponding to the electrical-mobility diameter mode selected by the DMA during experiments. Particle volume is thus obtained as $V_{p}=$ $\frac{\pi}{6} D_{p}^{3}$, without any mobility shape-factor correction. Particle compositions are given by the relative mass fractions $\left(W_{p}\right)$ of molecular surfactant (SFT) and $\mathrm{NaCl}$, where $W_{p, \mathrm{SFT}}+$ $W_{p, \mathrm{NaCl}}=1$. As mentioned in Sect. 2.1, these are assumed to reflect the weighed solute mass-fractions in the atomizer solutions (see Table 1). The total molar amounts $\left(n_{i}^{T}\right)$ of surfactant and $\mathrm{NaCl}$ solute $(i=\mathrm{SFT}, \mathrm{NaCl})$ available in the activating droplets are then calculated, assuming volume additivity of the dry particle components, from

$n_{i}^{T}=\frac{W_{p, i}}{M_{i}} \frac{\pi}{6} D_{p}^{3}\left(\frac{W_{p, \mathrm{SFT}}}{\rho_{\mathrm{SFT}}}+\frac{W_{p, \mathrm{NaCl}}}{\rho_{\mathrm{NaCl}}}\right)^{-1}$

Unit mass density is assumed for each of the fatty acid salts $\left(\rho_{\text {FAS }}=1 \mathrm{gcm}^{-3}\right)$, owing to lack of bulk-density information for the pure solid FAS.

For growing droplets, the total molar amount of water $\left(n_{w}^{T}\right)$ is calculated as a function of diameter $(d)$, assuming volume additivity of water and dry particle components within the aqueous droplets, as

$n_{w}^{T}=\frac{\rho_{w}}{M_{w}} \frac{\pi}{6}\left(d^{3}-D_{p}^{3}\right)$

All particle components are assumed to be completely dissolved in the droplet solution, equivalent to assuming full water solubility of both surfactant and $\mathrm{NaCl}$ solutes. Chemical reactions within the droplet solutions and physical reactions, such as condensation or evaporation of droplet and gas-phase components, are assumed to be absent. For each droplet size and corresponding total composition $\left(n_{i}^{T}, n_{w}^{T}\right)$, the droplet bulk-phase molar composition $\left(n_{i}^{B}, n_{w}^{B}\right)$ is subsequently determined, either without consideration of surface partitioning, as simply equated to the total droplet composition $\left(n_{i}^{B}=n_{i}^{T}, n_{w}^{B}=n_{w}^{T}\right)$, or from iterating the partitioning equilibrium, as described in the following Sect. 4.2.

Water activity and surface tension are evaluated as functions of the droplet solution bulk-phase composition according to relations for a macroscopic solution, such that $a_{w}=$ $a_{w}^{B}\left(n_{i}^{B}, n_{w}^{B}\right)$ and $\sigma=\sigma^{B}\left(n_{i}^{B}, n_{w}^{B}\right)$. Droplet solutions are assumed to be ideal and bulk-phase concentrations are therefore used instead of the appropriate activities for all droplet components. In particular, the droplet bulk-phase water activity is set equal to the corresponding water mole-fraction concentration $\left(a_{w}^{B}=x_{w}^{B}\right)$. Both surfactant and $\mathrm{NaCl}$ solutes are assumed to be fully dissociated in the droplet solution, with dissociation factors $\delta_{\mathrm{SFT}}=\delta_{\mathrm{NaCl}}=2$. Furthermore, the partial molar volume of water $\left(v_{w}\right)$ is approximated with the molar volume of pure water, given by the water molar mass and mass density as $\nu_{w}^{0}=M_{w} / \rho_{w}$, according to the assumption of volume additivity for all droplet components. Droplet surface tension is either evaluated from a concentration-dependent ternary SFT-NaCl aqueous solution surface tension parametrization, $\sigma=\sigma\left(c_{\mathrm{SFT}}^{B}, c_{\mathrm{NaCl}}^{B}\right)$, as described in Sect. 4.3 below, or set equal to the constant value for pure water $\left(\sigma=\sigma_{w}\right)$. Then, the equilibrium water saturation ratio $(S)$ for the given droplet size $(d)$ is finally calculated from Eq. (1).

Köhler model predictions are made with three different representations of surfactant properties:

1. (denoted " $\sigma, p$ ") explicitly accounting for bulk-surface partitioning in the droplets upon evaluating both Raoult and Kelvin terms in Eq. (1) and using a concentrationdependent droplet surface tension,

2. (denoted " $\sigma, b$ ") neglecting the effects of surface partitioning on droplet bulk-phase composition, but still using a concentration-dependent droplet surface tension, that is, evaluating both Raoult and Kelvin terms directly corresponding to a macroscopic (bulk aqueous) solution with the same total composition, and

3. (denoted " $\sigma_{w}$ ") completely disregarding surfactant properties of the organic and treating it as a common 
Table 2. Physical properties of the studied compounds used in model calculations: molar mass $M\left[\mathrm{gmol}^{-1}\right]$, dissociation factor $\delta$, and bulk mass-density $\rho\left[\mathrm{gcm}^{-3}\right]$. In all cases we have assumed $\delta=2$, and for the fatty acid salts we assumed $\rho_{\mathrm{FAS}}=1 \mathrm{gcm}^{-3}$.

\begin{tabular}{cccc}
\hline molecular formula & $M\left[\mathrm{gmol}^{-1}\right]$ & $\delta$ & $\rho\left[\mathrm{gcm}^{-3}\right]$ \\
\hline $\mathrm{CH}_{3}\left(\mathrm{CH}_{2}\right)_{6} \mathrm{COONa}$ & 166.2 & 2 & 1 \\
$\mathrm{CH}_{3}\left(\mathrm{CH}_{2}\right)_{8} \mathrm{COONa}$ & 194.2 & 2 & 1 \\
$\mathrm{CH}_{3}\left(\mathrm{CH}_{2}\right)_{10} \mathrm{COONa}$ & 222.3 & 2 & 1 \\
$\mathrm{CH}_{3}\left(\mathrm{CH}_{2}\right)_{10} \mathrm{OSO}_{3} \mathrm{Na}$ & 288.4 & 2 & 1.176 \\
$\mathrm{NaCl}$ & 58.44 & 2 & 2.165 \\
\hline
\end{tabular}

solute, by neglecting surface partitioning and using the constant surface tension of pure water $\left(\sigma_{w}\right)$ throughout droplet growth and activation.

Calculations involved in the partitioning representation are described in more detail in the following Sect. 4.2, and the concentration-dependent surface tension parameterizations are given in Sect. 4.3. Model assumptions are summarized in Sect. 4.4. Physical properties of the surfactants and $\mathrm{NaCl}$ used in the calculations are given in Table 2.

\subsection{Partitioning model}

To determine the bulk-surface partitioning equilibrium, the surface phase is defined as an infinitely thin region separating the droplet bulk-phase from the gas phase (Gibbs et al., 1928). The position of the surface is selected to yield the bulk-phase volume $\left(V^{B}\right)$ equal to the total (equimolar) droplet volume $\left(V^{T}\right)$ of all droplet components $j$

$V^{B}=\sum_{j} n_{j}^{B} v_{j}=\sum_{j} n_{j}^{T} v_{j}=V^{T}=V$

where $v_{j}$ is the partial molar volume of $j$. This ensures consistency with the assumption that the droplet surface tension is independent of droplet size (Sorjamaa et al., 2004).

Bulk-phase concentrations $\left(c_{j}^{B}\right)$ of all droplet components are evaluated by solving the the Gibbs adsorption equation (Gibbs et al., 1928)

$\sum n_{j}^{T} R T d \ln \left(a_{j}^{B}\right)+A d \sigma=0$

where $A\left[\mathrm{~m}^{2}\right]$ is the spherical droplet surface area, $\sigma=$ $\sigma^{B}\left[\mathrm{Nm}^{-1}\right]$ is droplet surface tension, given as function of bulk-phase composition, and $n_{j}^{T}[\mathrm{~mol}]$ is the total molar amount and $a_{j}^{B}\left(\equiv \gamma_{j}^{B} c_{j}^{B}\right)$ is the bulk-phase activity (with corresponding activity coefficient $\gamma_{j}^{B}$ ) of $j$. Mole-fraction based activities are used for all droplet components and, equivalent to the Köhler calculations described in Sect. 4.1 above, bulk-phase activities are approximated with the corresponding concentrations by assuming $\gamma_{j}^{B}=1$ for all species. Thus, $a_{j}^{B}=x_{j}^{B}$, where $x_{j}^{B}$ is the bulk-phase mole fraction of $j$. As both surfactant and $\mathrm{NaCl}$ solutes are assumed to be fully dissociated, droplet solutions thus comprise water $(w)$, organic surfactant anion $\left(\mathrm{SFT}^{-}\right)$, and inorganic sodium $\left(\mathrm{Na}^{+}\right)$and chloride $\left(\mathrm{Cl}^{-}\right)$ions. Concentrations are still reported for the respective formula units of both organic and inorganic salts, since the droplet bulk and surface phases must each be electrically neutral.

The number of independent variables in Eq. (5) is reduced by noting that droplet component total molar amounts, as evaluated from Eqs. (2) and (3) with the assumed dissociation factors, are conserved upon partitioning

$n_{j}^{T}=n_{j}^{B}+n_{j}^{S}$

Assuming the partial molar volume of each droplet component is the same in both bulk and surface phases, the partitioning equilibrium also conserves droplet component total volumes

$V_{j}^{T}=V_{j}^{B}+V_{j}^{S}$

where $V_{j}^{T}=n_{j}^{T} v_{j}$ and analogously for $V_{j}^{B}$ and $V_{j}^{S}$. Eq. (4) implies $V^{S}=\sum_{j} n_{j}^{S} v_{j}=0$; thus, if some species has enhanced surface molar number $\left(n_{j}^{S}>0\right)$, the corresponding surface volume $\left(V_{j}^{S}\right)$ must be balanced by simultaneous depletion of an equivalent volume of the remaining species from the surface. By furthermore assuming that water and $\mathrm{NaCl}$ have fixed molar ratios (Sorjamaa et al., 2004)

$\frac{n_{w}^{B}}{n_{\mathrm{NaCl}}^{B}}=\frac{n_{w}^{T}}{n_{\mathrm{NaCl}}^{T}}$

only a single independent variable, the surfactant anion bulkphase molar amount $\left(n_{\mathrm{SFT}^{-}}^{B}\right)$, remains. This quantity is found by numerically solving

$\sum n_{j}^{T} R T \frac{d \ln \left(a_{j}^{B}\right)}{d n_{\mathrm{SFT}^{-}}^{B}}+A \frac{d \sigma^{B}}{d n_{\mathrm{SFT}^{-}}^{B}}=0$

for each dry particle size $\left(D_{p}\right)$ and composition $\left(W_{p, \mathrm{SFT}}\right)$, and for one droplet size $(d)$ at a time, corresponding to known total molar amounts $\left(n_{j}^{T}\right)$ of all droplet components.

For a given value of $n_{\mathrm{SFT}}^{B}\left(=n_{\mathrm{SFT}^{-}}^{B}\right)$, bulk-phase molar amounts of all other droplet species $(i \neq$ SFT $)$ are related to this quantity by

$$
\begin{aligned}
V-n_{\mathrm{SFT}}^{B} v_{\mathrm{SFT}} & =\sum_{k \neq \mathrm{SFT}} n_{k}^{B} v_{k} \\
& =\frac{n_{i}^{B}}{n_{i}^{T}} \sum_{k \neq \mathrm{SFT}} n_{k}^{T} v_{k} \\
& =\frac{n_{i}^{B}}{n_{i}^{T}}\left(V-n_{\mathrm{SFT}}^{T} v_{\mathrm{SFT}}\right)
\end{aligned}
$$

whence

$n_{i}^{B}=n_{i}^{T} \frac{V-n_{\mathrm{SFT}}^{B} v_{\mathrm{SFT}}}{V-n_{\mathrm{SFT}}^{T} v_{\mathrm{SFT}}}$ 
Droplet surface tension $\left(\sigma^{B}\right)$ and bulk-phase activities of dissociated species $\left(a_{j}^{B}\right)$ are given from the component molar amounts, under the assumptions mentioned here and in Sect. 4.1 above. With these quantities, $n_{\mathrm{SFT}^{-}}^{B}$ is iterated from Eq. (9), until a solution is found.

\subsection{Surface tension parameterizations}

Model representations $\sigma, p$ and $\sigma, b$ employ concentrationdependent equilibrium surface tensions for the growing droplets (Prisle et al., 2008). Experimental ternary surfactant- $\mathrm{NaCl}$ bulk aqueous solution surface tensions were obtained from Prisle et al. (2010b) for the fatty acid salts (FAS), and from Rehfeld (1967) and Matijevic and Pethica (1958) for SDS. Surface tensions were parameterized as functions of both surfactant and $\mathrm{NaCl}$ bulk-phase concentrations by fitting data with the Szyskowski equation (Szyskowski, 1908). Experimental surface tensions decrease with increasing respective concentrations of both surfactant and $\mathrm{NaCl}\left(c_{\mathrm{SFT}}, c_{\mathrm{NaCl}}\right)$, over the reported ranges. For a given $c_{\mathrm{NaCl}}$, the surfactant strength in the ternary aqueous solutions, in terms of the surface tension reduction from the pure water value $\left(\sigma_{w}-\sigma\right)$ attained for a given $c_{\mathrm{SFT}}$, increases in the same order as for the corresponding binary surfactant bulk aqueous solutions, as $\mathrm{C} 8 \mathrm{Na}<\mathrm{C} 10 \mathrm{Na}<\mathrm{C} 12 \mathrm{Na}<\mathrm{SDS}$.

For the FAS- $\mathrm{NaCl}$ solutions, the Szyskowski equation was fitted to experimental surface tensions in the form:

$\sigma=\sigma_{w}+\left(\frac{d \sigma_{\mathrm{NaCl}}}{d m_{\mathrm{NaCl}}}\right) m_{\mathrm{NaCl}}-a \ln \left(1+m_{\mathrm{FAS}} / b\right)$

where $m_{\mathrm{NaCl}}$ and $m_{\mathrm{FAS}}$ are the $\mathrm{NaCl}$ and FAS molal concentrations (moles of solute species per kilogram of water) and $\sigma_{w}=72.2 \mathrm{mNm}^{-1}$ is the pure water surface tension at $296.65 \mathrm{~K}$. The surface tension gradient for aqueous $\mathrm{NaCl}$, $\left(\frac{d \sigma_{\mathrm{NaCl}}}{d m_{\mathrm{NaCl}}}\right)=1.61\left[\mathrm{mN} \mathrm{m}^{-1} / \mathrm{mol} \mathrm{kg}^{-1}\right]$, is obtained by linear fitting to data from Vanhanen et al. (2008). Szyskowski equation fitting-parameters $a$ and $b$ depend on the relative FAS and $\mathrm{NaCl}$ solute mass-fractions, where $w_{\mathrm{FAS}}+w_{\mathrm{NaCl}}=1$, as

$a=a_{1}+a_{2} w_{\mathrm{FAS}}+a_{3} w_{\mathrm{FAS}}{ }^{2}$

$b=b_{1}+b_{2} w_{\mathrm{FAS}}+b_{3} w_{\mathrm{FAS}}{ }^{2}$

Fitted parameters are given in Table 3. Note that, due to surface partitioning, $w_{\mathrm{FAS}}$ and $w_{\mathrm{NaCl}}$ are generally not equal to the corresponding total dry particle mass-fractions ( $W_{p, \mathrm{FAS}}$ and $\left.W_{p, \mathrm{NaCl}}\right)$.

The SDS- $\mathrm{NaCl}$ solution surface tension parametrization is obtained from the Szyskowski equation with SDS and $\mathrm{NaCl}$ molar concentrations (moles of solute species per liter of solution) $c_{\mathrm{SDS}}$ and $c_{\mathrm{NaCl}}$ :

$\sigma=\sigma_{w}+\left(\frac{d \sigma_{\mathrm{NaCl}}}{d c_{\mathrm{NaCl}}}\right) c_{\mathrm{NaCl}}-a \ln \left(1+c_{\mathrm{SDS}} / b\right)$

As solutions are dilute, the same numerical value is used for the binary $\mathrm{NaCl}$ surface tension gradient with
Table 3. Szyskowski (Eq. 14) fitting parameters for ternary FAS-NaCl aqueous surface tension parameterizations. Units are $\mathrm{mN} \mathrm{m}^{-1}$ and mol kg ${ }^{-1}$ for parameters $a$ and $b$, respectively.

\begin{tabular}{lllllll}
\hline & $a_{1}$ & $a_{2}$ & $a_{3}$ & $b_{1}$ & $b_{2}$ & $b_{3}$ \\
\hline C8Na & 36.82 & 17.63 & 0 & 0.0119 & 0.0744 & 0 \\
C10Na & 40.10 & 8.06 & -26.32 & 0.006 & 0.041 & -0.034 \\
C12Na & 48.98 & -0.88 & 0 & 0.004 & 0.004 & 0 \\
\hline
\end{tabular}

respect to molar and molal concentrations, so that $\left(\frac{d \sigma_{\mathrm{NaCl}}}{d c_{\mathrm{NaCl}}}\right)=1.61\left[\mathrm{mN} \mathrm{m}^{-1} / \mathrm{mol} \mathrm{L}^{-1}\right]$. Fitted parameters are $a=13.9 \mathrm{mN} \mathrm{m}^{-1}$ and $b=\left(9.27 \mathrm{E}-6 \mathrm{~mol}^{2} \mathrm{~L}^{-2}\right) /\left(c_{\mathrm{NaCl}}+\right.$ $\left.9.73 \mathrm{E}-3 \mathrm{~mol} \mathrm{~L}^{-1}\right)$. A ternary SDS- $\mathrm{NaCl}$ aqueous solution surface tension parametrization, based on the same data from Rehfeld (1967) and Matijevic and Pethica (1958), is also provided by Li et al. (1998). This parametrization is however not continuous, which would cause problems in our calculations, and therefore the new parametrization was made.

Surfactants can form micelles in concentrated aqueous solutions above the so-called critical micelle concentration $(\mathrm{cmc})$. Micelles are aggregate structures in which the amphiphilic surfactant molecules are oriented with the polar head-groups facing the aqueous medium, thus shielding a core consisting of the non-polar hydrocarbon tails (Corrin and Harkins, 1947). As micelles begin to form, the surface tension gradient with respect to increasing concentrations of dissolved surfactant sharply levels off and the surface tension becomes approximately constant. Surface tension parameterizations were here obtained by fitting data corresponding to surface tension values above those at the respective ternary solution cmcs, estimated by visual inspection of the data. In the Köhler model calculations, these constant values are furthermore imposed as lower limits for the droplet surface tensions evaluated from the resulting continuous parameterizations in each case. The minimum ternary solution surface tensions estimated from the data were 24, 27, 22, and $22 \mathrm{mNm}^{-1}$ for $\mathrm{C} 8 \mathrm{Na}, \mathrm{C} 10 \mathrm{Na}, \mathrm{C} 12 \mathrm{Na}$, and SDS, respectively. It must be noted, that ternary solution cmcs and minimum surface tensions will in general depend on both surfactant and salt solutes.

\subsection{Summary of model assumptions}

- Equilibrium is established between different phases within the droplet solution systems and with respect to the surroundings, and no kinetic effects influence solution properties or droplet growth and activation.

- Dry particles are spherical, such that the volumeequivalent diameter equals the selected electricalmobility diameter and no mobility shape-factor is applied. 
- Dry particle mass-fraction compositions reflect those of the solutes within the atomizer solutions from which particles are generated.

- All components in the dry particle mixtures and aqueous droplet solutions have zero excess mixing volumes.

- Fatty acid sodium salt bulk mass-densities are all unity.

- No chemical or physical reactions change the overall compositions of the droplet systems.

- All dry particle components are infinitely soluble in the aqueous droplet solutions.

- All species in solution are fully dissociated.

- All components behave ideally in the aqueous droplet solution, by having unit activity coefficients on the concentration scales of their respective activity reference states.

- Droplet solution surface tensions are limited to the estimated minimum values at the approximate ternary cmcs.

- The droplet surface is an infinitely thin spherical shell with zero volume, such that the droplet bulk-phase volume equals the total equimolar droplet volume.

- The partitioning equilibrium conserves total molar amounts and volumes of the individual droplet components.

- The molar ratios of droplet species other than surfactant are fixed.

\section{Results and discussion}

\subsection{Experimental observations}

Figure 1 shows measured critical supersaturations $\left(S S_{c}^{\exp }\right)$ as a function of selected dry particle mobility-diameter $\left(D_{p}\right)$ for the mixed surfactant- $\mathrm{NaCl}$ particles. Individual panels (a)-(d) display results for increasing surfactant (SFT) massfractions in the dry particles $\left(W_{p, \mathrm{SFT}}\right)$. In panels (a) and (b), it is seen that with $W_{p, \mathrm{SFT}} \leq 50 \%$, differences in $S S_{c}^{\exp }$ for particles of a given $D_{p}$ comprising different surfactants are comparable to experimental uncertainties. Any potential differences in droplet activation behavior due to individual molecular properties of the surfactants are thus dominated by the presence of the inorganic salt. Panels (c) and (d), on the other hand, show that, when $W_{p, \mathrm{SFT}}>50 \%$, particles with a given surfactant mass-fraction for each $D_{p}$ activate with $S S_{c}^{\exp }$ increasing in the order of increasing surfactant molecular mass $\left(M_{\mathrm{SFT}}\right)$, as $\mathrm{C} 8 \mathrm{Na}<\mathrm{C} 10 \mathrm{Na}<\mathrm{C} 12 \mathrm{Na}<\mathrm{SDS}$. It should be noted that, in panel (c), $W_{p, \mathrm{C} 10 \mathrm{Na}}=73 \%$ is somewhat lower than for the other surfactants $(\sim 80 \%)$, which affects the apparent trend in $S S_{c}^{\exp }$ with $M_{\mathrm{SFT}}$.

We have previously observed single-component particles of these same surfactants to similarly activate with $S S_{c}^{\exp }$ increasing in the order of increasing $M_{\mathrm{SFT}}$ (Sorjamaa et al., 2004; Prisle et al., 2008). As noted in Sect. 4.3, surfactant strength also increases with increasing $M_{\mathrm{SFT}}$ in both binary SFT (Campbell and Lakshminarayanan, 1965) and ternary SFT-NaCl (Matijevic and Pethica, 1958; Rehfeld, 1967; Prisle et al., 2010b) bulk aqueous solutions. For activating solution droplets formed on pure surfactant particles of a given $D_{p}$, any effect of enhanced surface tension reduction with increasing surfactant strength was insufficient to overcome the decrease in Raoult effect arising directly from the increase in $M_{\mathrm{SFT}}$ and possibly also from enhanced droplet bulk-phase depletion by surface partitioning of the stronger surfactants.

Inorganic salts can influence individual organic surfactant properties, as seen for the ternary SFT-NaCl bulk aqueous solution surface tensions in Sect. 4.3. Increased organic activity in an aqueous salt solution can decrease the corresponding solubility and lead to precipitation or enhanced surface partitioning. This is often called the "salting-out effect" (Lin et al., 2005; Tuckermann, 2007; Vanhanen et al., 2008). In macroscopic solutions, enhanced surface partitioning may increase surfactant strength. In microscopic droplets with large surface-area-to-bulk-volume ratios, it will however also increase bulk-phase depletion of dissolved surfactant molecules. The resulting effect of organic-inorganic interactions on droplet surface tension and surfactant activation properties is therefore not immediately anticipated. Properties of inorganic salts also directly influence cloud droplet activation of the mixed particles. The molecular mass of $\mathrm{NaCl}$ is lower than for any of the studied surfactants (see Table 2). Therefore, dissolved $\mathrm{NaCl}$ by dry particle mass-fraction contributes a larger Raoult effect in the solution droplets formed than the organics, even in the absence of surfactant partitioning.

The present results for mixed SFT-NaCl particles show that, when $\mathrm{NaCl}$ comprises half, or more, of the dry particle mass, the larger Raoult effect of the inorganic salt appears to dominate any mutual differences in surfactant molecular properties for determining droplet activation. On the other hand, for particles with each surfactant comprising more than half of the mass, the effects of individual surfactant properties become evident. Still, at a given $W_{p, \mathrm{SFT}}$, just as for the pure surfactant particles, any increased droplet surface tension reduction with increasing surfactant strength evidently cannot overcome the simultaneous decrease in Raoult effect from increased $M_{\mathrm{SFT}}$ and possibly enhanced surface partitioning.

Comparing results for the individual surfactants between panels (a)-(d) in Fig. 1 shows that $S S_{c}^{\exp }$ for a given $D_{p}$ increases with increasing $W_{p \text {,SFT }}$ in the dry particles. This 
(a) $\sim 20 \%$ surfactant $+80 \% \mathrm{NaCl}$

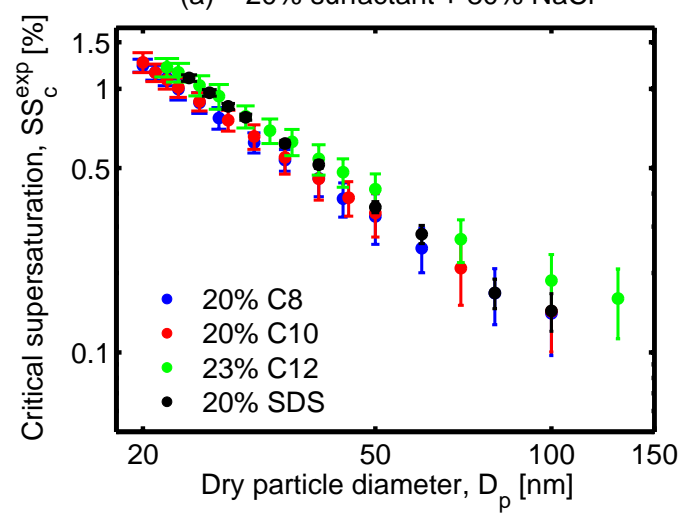

(c) $~ 80 \%$ surfactant $+20 \% \mathrm{NaCl}$

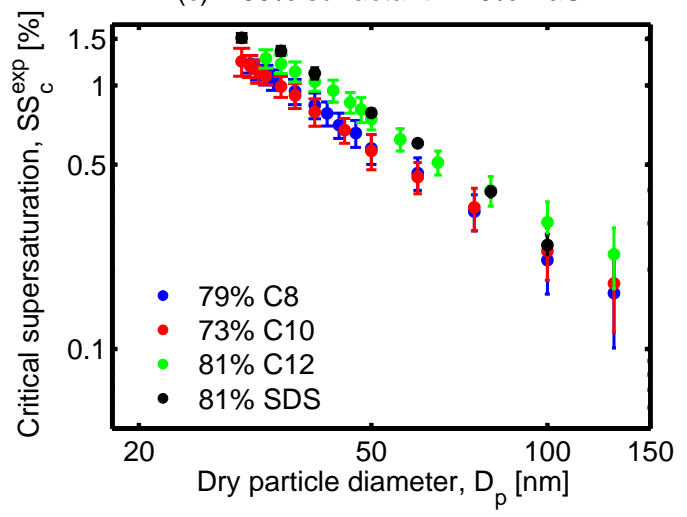

(b) $\sim 50 \%$ surfactant $+50 \% \mathrm{NaCl}$

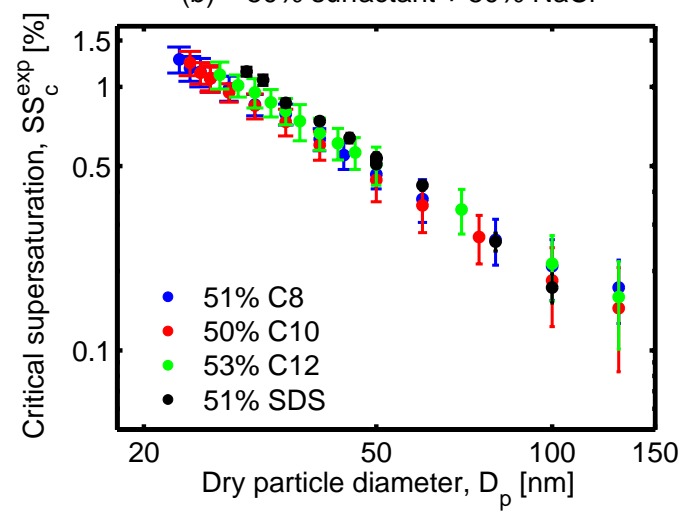

(d) $~ 95 \%$ surfactant $+5 \% \mathrm{NaCl}$

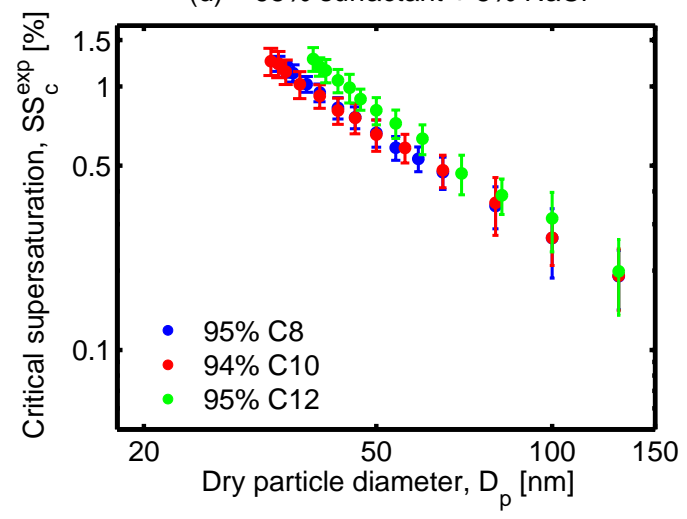

Fig. 1. Experimental critical supersaturations $\left(S S_{c}^{\exp }[\%]\right)$ as a function of dry particle diameter $\left(D_{p}\right.$ [nm]) for all dry particle compositions. Individual panels show results for approximate surfactant mass fractions ( $\left.W_{p, \mathrm{SFT}}\right)$ of (a) 20\%, (b) $50 \%$, (c) $80 \%$ and (d) $95 \%$.

was also observed by Rood and Williams (2001) for mixed $\mathrm{SDS}-\mathrm{NaCl}$ particles. Thus, as $\mathrm{NaCl}$ is gradually replaced by surfactant in the dry particles, any reduction in droplet surface tension and Kelvin effect is dominated by the decrease in Raoult effect, from increasing particle component mean molecular mass (as $M_{\mathrm{SFT}}>M_{\mathrm{NaCl}}$ ) and potentially also from an increased degree of bulk-phase depletion due to surface partitioning, as the surfactant comprises a larger fraction of the total amount of solute within the droplets.

\subsection{Comparison with Köhler model predictions}

Experimental critical supersaturations $\left(S S_{c}^{\mathrm{exp}}\right)$ are compared to Köhler model predictions with each of the three different surfactant representations $\left(S S_{c}^{\sigma, p}, S S_{c}^{\sigma, b}\right.$, and $\left.S S_{c}^{\sigma_{w}}\right)$ in Figs. $2(\mathrm{C} 8 \mathrm{Na}), 3(\mathrm{C} 10 \mathrm{Na}), 4(\mathrm{C} 12 \mathrm{Na})$, and 5 (SDS).

It is immediately clear that the bulk solution representation $(\sigma, b)$ greatly underpredicts $S S_{c}^{\exp }$ for all dry particle sizes and compositions studied here. Predicted critical supersaturations $\left(S S_{c}^{\sigma, b}\right)$ are well outside the range of experimental uncertainty in all cases. The simple solute representation $\left(\sigma_{w}\right)$ in many cases predict $S S_{c}^{\exp }$ well, in particular for the less strong surfactants. However, $\sigma_{w}$ can also lead to significant underpredictions of experimental values, albeit to a much lesser degree than $\sigma, b$. The partitioning representation $(\sigma, p)$ generally describes experimental activation behavior well. Specifically, for the mixed particles comprising SDS, $\sigma, p$ is consistently superior to the bulk property representations $\left(\sigma, b\right.$ and $\left.\sigma_{w}\right)$ over the full ranges of dry particle sizes and compositions studied here. For particles comprising one of the fatty acid salts (FAS), $\sigma, p$ in some cases overpredicts $S S_{c}^{\exp }$ : generally, this occurs for the smaller particles comprising the larger mass fractions of the stronger surfactants.

For the largest particles comprising FAS, all surfactant representations underpredict $S S_{c}^{\mathrm{exp}}$. For particles with FAS, the $\log S S_{c}-\log D_{p}$ slope is generally steeper for model predictions than observed experimentally. This suggests that there may be some size-dependent effect not accounted for with the equilibrium Köhler model used here. Possible sizedependent effects on dry particle properties and droplet activation are discussed in more detail in Sect. 5.4 below.

Figure 6 shows measured $\left(S S_{c}^{\exp }\right)$ and model predicted $\left(S S_{c}^{\sigma, p}, S S_{c}^{\sigma, b}\right.$, and $\left.S S_{c}^{\sigma_{w}}\right)$ critical supersaturations for particles of selected dry sizes as functions of dry particle 

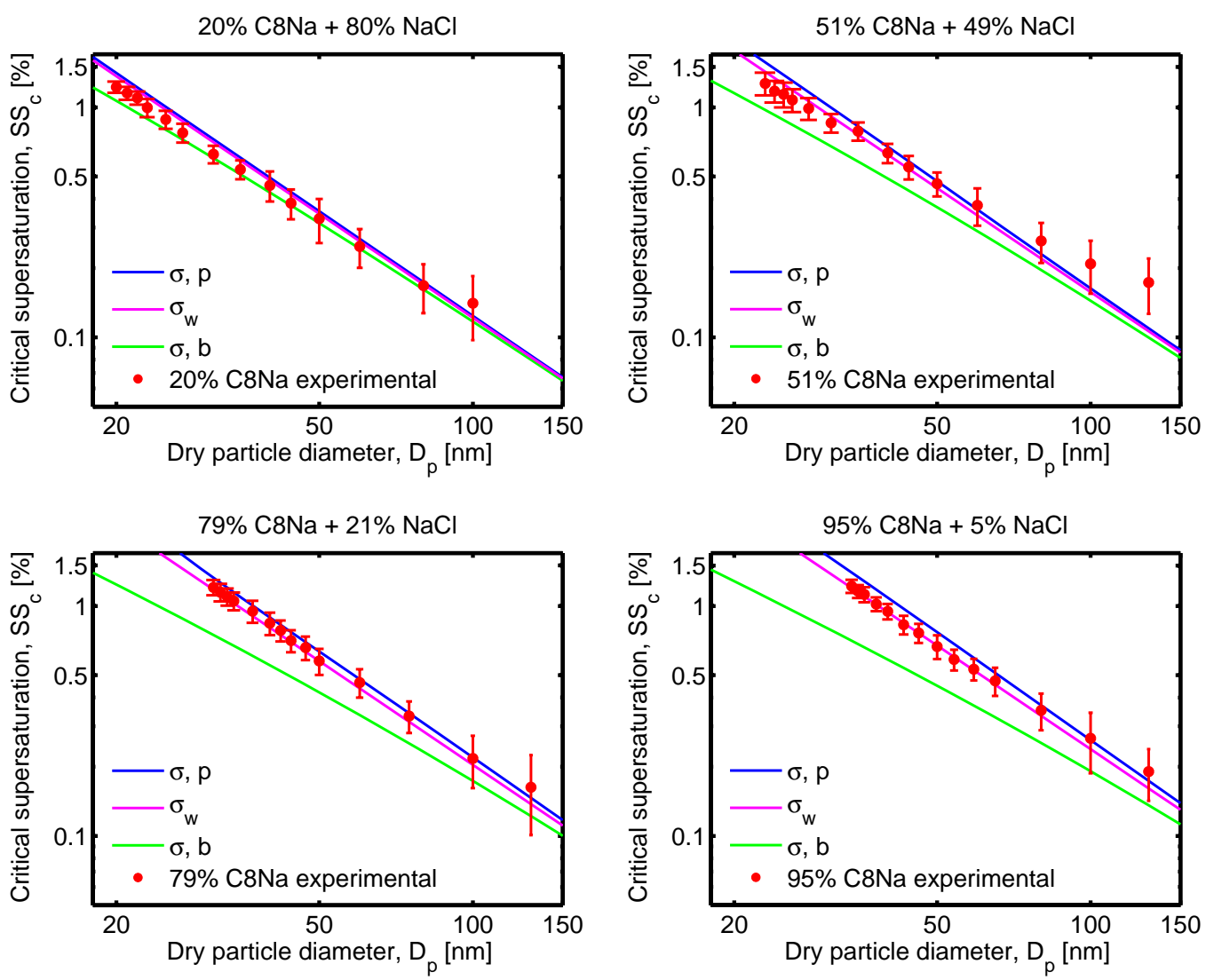

Fig. 2. Critical supersaturations $\left(S S_{c}[\%]\right)$ as functions of dry particle diameter $\left(D_{p}[\mathrm{~nm}]\right)$ for particles with sodium octanoate $(\mathrm{C} 8 \mathrm{Na})$ in dry mass fractions $\left(W_{p, \mathrm{C} 8 \mathrm{Na}}\right)$ of (a) $20 \%$, (b) $51 \%$, (c) $79 \%$, and (d) $95 \%$, measured in experiments and modeled with the three different surfactant representations $\left(\sigma, p, \sigma, b\right.$, and $\left.\sigma_{w}\right)$.

surfactant mass-fraction $\left(W_{p, \mathrm{SFT}}\right)$. Each panel shows results for one of the surfactants studied. Upper curves and data points are results for $D_{p}=40 \mathrm{~nm}$, representing the "smaller" particle sizes, and lower curves and data points are results for $D_{p}=100 \mathrm{~nm}$, representing the "larger" particles studied. Experimental critical supersaturations reported for pure surfactant particles (Sorjamaa et al., 2004; Prisle et al., 2008) and mixed SDS-NaCl particles (Rood and Williams, 2001) in previous studies, and critical supersaturations measured for pure $\mathrm{NaCl}$ particles during calibration of the CCNC in the present work, are included for comparison. The perspective presented in Fig. 6 elaborates on the findings of Figs. 2, 3,4 , and 5 . In all cases, the underpredictions of $S S_{c}^{\mathrm{exp}}$ by $\sigma, b$ increase with increasing surfactant mass-fraction in the dry particles. The partitioning representation $(\sigma, p)$ generally describes experimental activation well, but overpredicts $S S_{c}^{\exp }$ for the smaller particles $\left(D_{p}=40 \mathrm{~nm}\right)$ with the largest mass-fractions $(\sim 95 \%)$ of FAS. The simple solute representation $\left(\sigma_{w}\right)$ also describes experimental activation well, in particular for the smaller $W_{p, \text { SFT }}$, but underpredicts $S S_{c}^{\exp }$ for the stronger surfactants (C12Na and SDS) when particles contain significant surfactant mass-fractions (e.g. $W_{p, \mathrm{SFT}}>$ $50 \%)$.

\subsection{Evaluation of surfactant representations}

Comparing model predictions using the different surfactant representations reveal some of the dynamics behind the effects of surfactant properties on cloud droplet activation for the mixed particles. The partitioning representation $(\sigma, p)$ accounts for the influence of surface partitioning on droplet bulk-phase composition and uses reduced droplet surface tension, as would be anticipated from the presence of watersoluble surfactants in the dry particles. It is therefore expected to provide the most comprehensive and thermodynamically consistent description of surfactant properties applied in the present Köhler calculations. In our previous work, $\sigma, p$ and the simple solute representation $\left(\sigma_{w}\right)$ nevertheless gave very similar predictions of critical supersaturations for single-component particles of the C8-C12 fatty acid salts (Prisle et al., 2008) and of SDS (Sorjamaa et al., 2004). This was due to mutual differences in the Kelvin and Raoult terms nearly canceling at the respective points of 

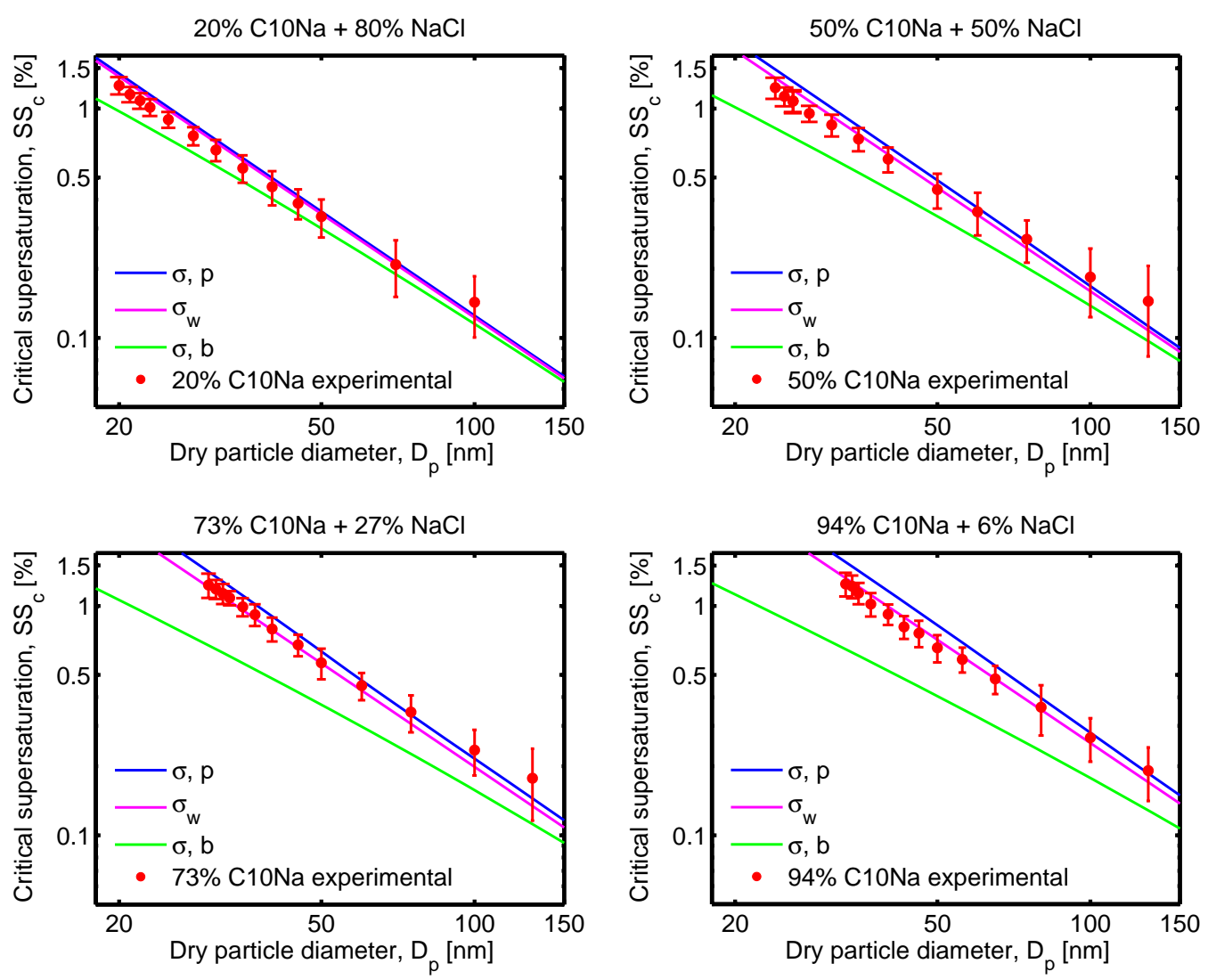

Fig. 3. Critical supersaturations $\left(S S_{c}[\%]\right)$ as functions of dry particle diameter $\left(D_{p}[\mathrm{~nm}]\right)$ for particles with sodium decanoate $(\mathrm{C} 10 \mathrm{Na})$ in dry mass fractions ( $W_{p, \mathrm{C} 10 \mathrm{Na}}$ ) of (a) 20\%, (b) 50\%, (c) 73\%, and (d) $94 \%$, measured in experiments and modeled with the three different surfactant representations $\left(\sigma, p, \sigma, b\right.$, and $\left.\sigma_{w}\right)$.

droplet activation, for the specific particle compositions studied and component properties applied. Specifically, for pure $\mathrm{C} 12 \mathrm{Na}$ particles, predicted $S S_{c}^{\sigma, p} \approx S S_{c}^{\sigma_{w}}$, whereas for pure $\mathrm{C} 8 \mathrm{Na}$ and pure $\mathrm{C} 10 \mathrm{Na}, S S_{c}^{\sigma, p}>S S_{c}^{\sigma_{w}}$, and for pure SDS, $S S_{c}^{\sigma, p}<S S_{c}^{\sigma_{w}}$.

Predicted cloud droplet activation for the mixed particles in the present study depends on the properties of both surfactant and $\mathrm{NaCl}$. The Raoult effect of the inorganic salt, as well as the influence of $\mathrm{NaCl}$ on surfactant properties of the organic, will affect the relative importance of the predicted Kelvin and Raoult effects within the activating droplets. Figures $2-5$ and 6 show that, for the mixed SFT-NaCl particles, $\sigma, p$ and $\sigma_{w}$ also produce similar results at the smaller surfactant mass-fractions (e.g. $W_{p, \mathrm{SFT}}<50 \%$ ). This supports the suggestion in relation to our experimental observations that, for these particle compositions, the large Raoult effect of $\mathrm{NaCl}$ dominates any differences in activation behavior arising from the different molecular properties of the surfactants (see Fig. 1). As the surfactants comprise larger massfractions within the dry particles (e.g. $W_{p, \mathrm{SFT}}>50 \%$ ), predicted $S S_{c}^{\sigma, p}>S S_{c}^{\sigma_{w}}$. Thus, even if $\mathrm{NaCl}$ increases surfactant strength in the macroscopic ternary solutions, the pre- dicted effect of enhanced surface partitioning is in these cases even greater on increasing the water activity in the activating droplets.

Differences between $S S_{c}^{\sigma, p}$ and $S S_{c}^{\sigma_{w}}$ increase with increasing $W_{p, \mathrm{SFT}}$, but the predictions eventually re-merge, as particles become almost pure surfactant (for $W_{p, \mathrm{SFT}} \rightarrow$ $100 \%$ ). Based on our previous model results for pure surfactant particles, predicted $S S_{c}-W_{p \text {,SFT }}$ curves with $\sigma, p$ and $\sigma_{w}$ would thus be expected to cross at some point, for SDS and C12Na. This cross-over is indeed observed for SDS (see Fig. 5$)$ at very high mass fractions ( $\left.W_{p, \text { SDS }} \approx 100 \%\right)$, but not for mixed particles with C12Na. Model calculations in the present work were made with new ternary aqueous solution surface tension parameterizations, as opposed to the binary surface tensions previously employed in calculations for pure FAS particles (Prisle et al., 2008) and the parameterization used for SDS-NaCl solutions by Sorjamaa et al. (2004). As a consequence, mixed particle predictions in the limit of $W_{p, \mathrm{SFT}}=100 \%$ are here made for somewhat different conditions than was previously applied for the pure surfactant particles. 

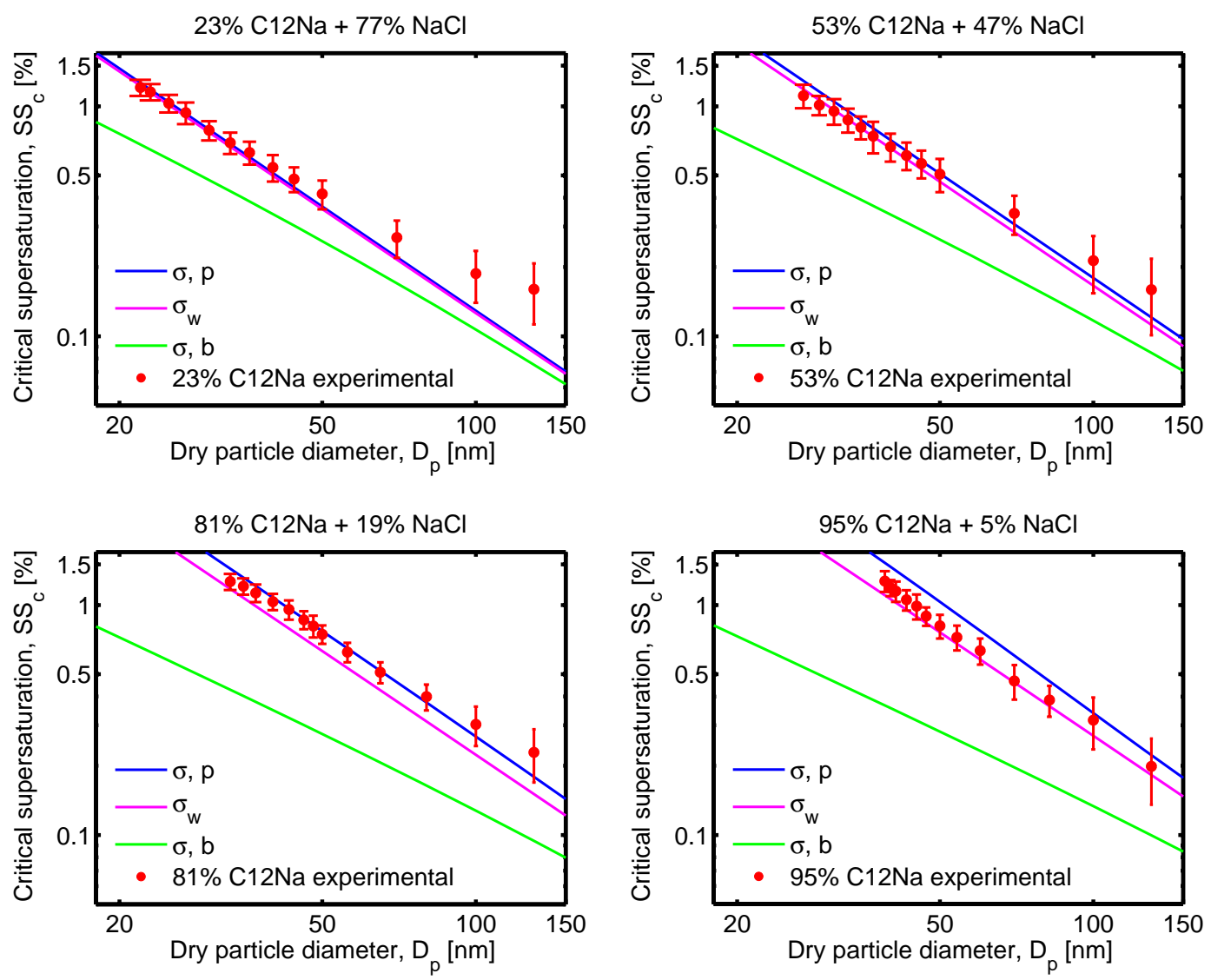

Fig. 4. Critical supersaturations $\left(S S_{c}[\%]\right)$ as functions of dry particle diameter $\left(D_{p}[\mathrm{~nm}]\right)$ for particles with sodium dodecanoate $(\mathrm{C} 12 \mathrm{Na})$ in dry mass fractions $\left(W_{p, \mathrm{C} 12 \mathrm{Na}}\right)$ of (a) $23 \%$, (b) $53 \%$, (c) $81 \%$, and (d) $95 \%$, measured in experiments and modeled with the three different surfactant representations $\left(\sigma, p, \sigma, b\right.$, and $\left.\sigma_{w}\right)$.

Predictions of $S S_{c}^{\sigma, p}>S S_{c}^{\sigma_{w}}$ may appear opposed to the decrease in critical supersaturations that could immediately be expected from the explicit dependency of the Kelvin term on reduced droplet surface tension (Shulman et al., 1996). However, predicted activation with the different surfactant representations generally occurs for different critical droplet diameters $\left(d_{c}\right)$. Even if the partitioning representation accounts for the reduced droplet surface tension, predicted critical supersaturations can still be higher than with the simple solute representation that completely disregards specific surfactant properties: this occurs when surface activity via surfactant partitioning causes an even greater suppression of the droplet Raoult effect than the Kelvin effect suppression attained from reduced droplet surface tension, at the respective $d_{c}$ s predicted with $\sigma, p$ and $\sigma_{w}$. Notably, when experimental values $S S_{c}^{\exp }>S S_{c}^{\sigma_{w}}$ for the mixed surfactant- $\mathrm{NaCl}$ particles, it thus suggests a real influence of surfactant partitioning effects within the activating cloud droplets.
Other studies have considered surfactant properties in activating droplets by using reduced surface tensions corresponding to macroscopic (bulk) aqueous solutions with the same overall composition (Shulman et al., 1996; Facchini et al., 1999; Dinar and Taraniuk, 2006; Svenningsson et al., 2006). Calculations have also been simplified by assuming droplets sufficiently dilute at the point of activation that the constant surface tension of pure water could be applied (Bilde and Svenningsson, 2004; Hartz et al., 2005). Li et al. (1998) and Rood and Williams (2001) partially accounted for surface partitioning in cloud droplet formation of mixed SDS-NaCl particles, by including the effect of bulk-phase depletion on predicted droplet surface tension. Li et al. (1998) showed that replacing $\mathrm{NaCl}$ with SDS in the dry particles increases predicted critical supersaturations. This result is analogous to those of our Köhler model predictions using the partitioning representation, although the detailed underlying mechanism is inherently somewhat different. Rood and Williams (2001) thus argue that "surfactants similar to SDS will inhibit the ability of $\mathrm{NaCl}$ particles to activate in clouds". Here, we confirm this suggestion experimentally and show 

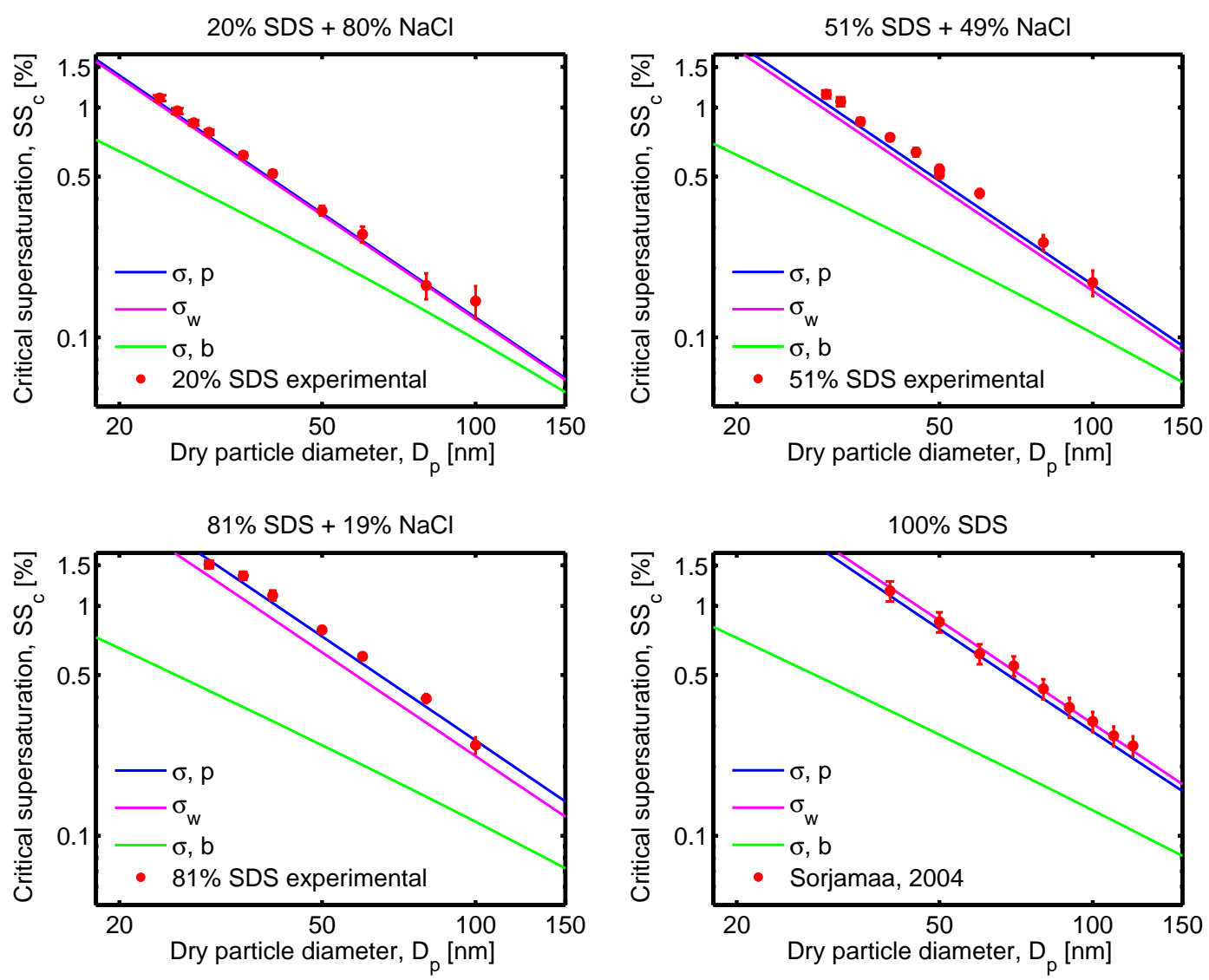

Fig. 5. Critical supersaturations $\left(S S_{c}[\%]\right)$ as functions of dry particle diameter $\left(D_{p}[\mathrm{~nm}]\right)$ for particles with sodium dodecyl sulfate (SDS) in dry mass fractions ( $W_{p, \mathrm{SDS}}$ ) of (a) 20\%, (b) $51 \%$, and (c) $81 \%$, measured in experiments and modeled with the three different surfactant representations $\left(\sigma, p, \sigma, b\right.$, and $\left.\sigma_{w}\right)$. Experimental results from Sorjamaa et al. (2004) for pure SDS are shown in panel (d) and compared to predictions with the model of the current study, using the compound parameters given in Table 2 .

for the first time, for a series of fatty acid sodium salts that occur in the real atmosphere, that displacing $\mathrm{NaCl}$ with surfactant significantly increases particle critical supersaturations.

Rood and Williams (2001) present experimental data for the $\mathrm{CCN}$ activity of mixed SDS- $\mathrm{NaCl}$ particles with similar compositions as was studied in this work. Their measured critical supersaturations follow the same trends with dry particle size and surfactant mass-fraction as presented here. Experimental $S S_{c}$ values given by Rood and Williams (2001) for particles comprising SDS are however consistently lower than ours and appear to be best described by our Köhler model calculations using the simple solute representation $\left(\sigma_{w}\right)$. As no experimental uncertainty estimates are given by Rood and Williams (2001), we however cannot say if the differences between the two experimental data sets are significant. Rood and Williams (2001) also do not provide details of the experimental conditions and the differences in observed activation could potentially be caused by temperature differences during measurements.
For all mixed particles comprising SDS studied here, the partitioning representation $(\sigma, p)$ gives the best prediction of experimental critical supersaturations $\left(S S_{c}^{\exp }\right)$. For particles comprising FAS, $\sigma, p$ and the simple solute representation $\left(\sigma_{w}\right)$ are both greatly superior to the bulk solution representation $(\sigma, b)$, but our current results do not provide a clear discrimination between $\sigma, p$ and $\sigma_{w}$ as the better representation for the studied FAS. Model calculations using $\sigma, p$ somewhat overpredict experimental critical supersaturations $\left(S S_{c}^{\sigma, p}>S S_{c}^{\exp }\right)$, especially for the smaller particles comprising the highest mass-fractions ( $\sim 95 \%)$ of FAS. For these particles, $\sigma_{w}$ on the other hand tends to underpredict experimental values $\left(S S_{c}^{\sigma_{w}}<S S_{c}^{\mathrm{exp}}\right)$.

Smaller dry particles activate with critical droplets corresponding to smaller diameter growth factors $\left(d_{c} / D_{p}\right)$, and thus with larger total solute concentrations $\left(c^{T} \propto\right.$ $\left.\left(d_{c} / D_{p}\right)^{-3}\right)$. The larger surface-area-to-bulk-volume ratios $\left(A / V \propto d_{c}^{-1}\right)$ of the smaller critical droplets however also facilitate greater relative surfactant bulk-phase depletions $\left(c^{S} / c^{B}\right)$. The smaller particles with the higher surfactant 
(a) $\mathrm{C} 8 \mathrm{Na}+\mathrm{NaCl}$ particles

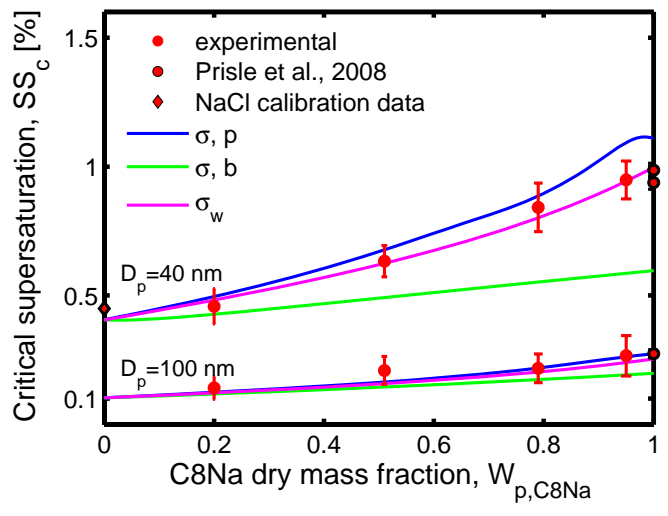

(c) $\mathrm{C} 12 \mathrm{Na}+\mathrm{NaCl}$ particles

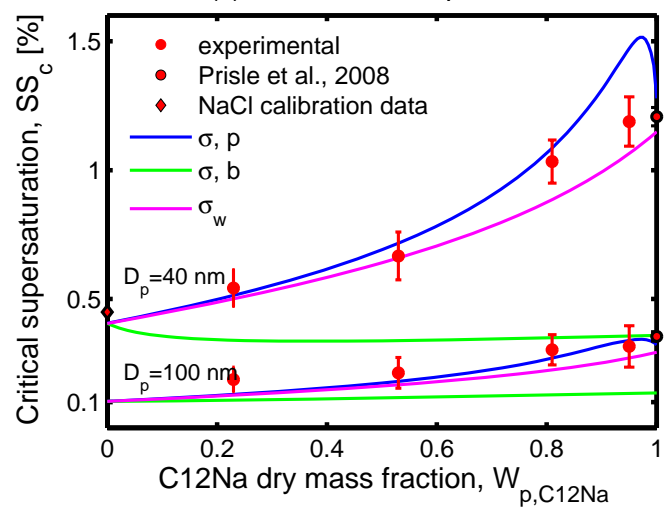

(b) $\mathrm{C} 10 \mathrm{Na}+\mathrm{NaCl}$ particles

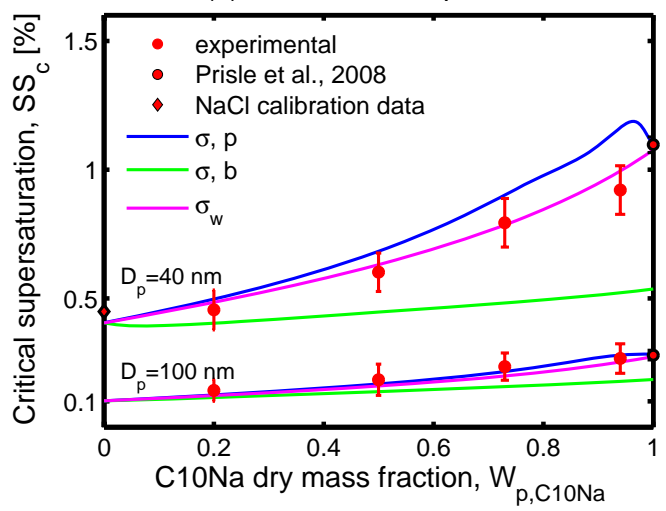

(d) $\mathrm{SDS}+\mathrm{NaCl}$ particles

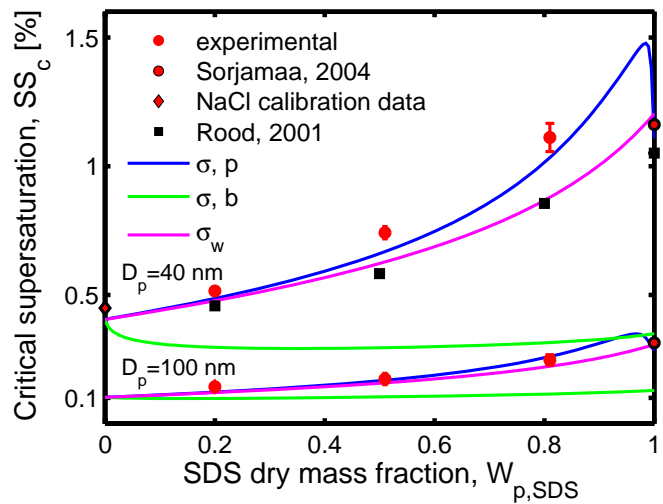

Fig. 6. Critical supersaturations $\left(S S_{c}[\%]\right)$ for particles with increasing dry mass fractions $\left(W_{p, \mathrm{SFT}}\right)$ of (a) sodium octanoate $(\mathrm{C} 8 \mathrm{Na})$, (b) sodium decanoate $(\mathrm{C} 10 \mathrm{Na})$, (c) sodium dodecanoate $(\mathrm{C} 12 \mathrm{Na})$, and (d) sodium dodecyl sulfate (SDS), measured in experiments and modeled with the three different surfactant representations $\left(\sigma, p, \sigma, b\right.$, and $\left.\sigma_{w}\right)$. Experimental values from Sorjamaa et al. (2004) and Prisle et al. (2008) for pure surfactant particles, and from Rood and Williams (2001) for mixed SDS-NaCl particles, as well as calibration data for pure $\mathrm{NaCl}$ particles, are included for comparison. Results are shown for selected dry particle sizes, $D_{p}=40 \mathrm{~nm}$ (upper curves and data points) and $D_{p}=100 \mathrm{~nm}$ (lower curves and data points).

mass-fractions thus accentuates the importance of a correct description of surfactant concentration and concentrationdependent surface tension and solution effects in the activating droplets.

The ternary FAS-NaCl solution surface tension parameterizations applied in our model calculations (see Sect. 4.3) are not constrained by measurements for bulk-phase massfractions $\left(w_{\text {FAS }}\right)$ relative to $\mathrm{NaCl}$ below about $20 \%$. In small droplets, surfactant surface partitioning can however yield very low predicted $w_{\text {FAS }}(<0.1 \%)$. The parameterizations used may therefore not reproduce the correct surface tension properties for such droplets. Test calculations indicate a significant effect of the surface tension parameterizations applied on predicted critical supersaturations, in particular with $\sigma, p$. Unfortunately, we do not at present have the experimental data to obtain better constraints on the Szyskowski fitting parameters. Future work should emphasize employing surface tension parameterizations that are well-constrained by measurements for bulk aqueous solution compositions corresponding to those predicted in the bulk-phase of activating solution droplets.

The sensitivity of our Köhler model predictions was tested to selected properties of the experimental systems, in particular to uncertainties in FAS mass-density, dry particle composition, size, and shape, and droplet solution effects in terms of non-ideality and solute dissociation and limited bulk-phase concentration. The sensitivity calculations are described in detail and selected results are presented in Appendix B. None of the tested effects proved capable of resolving the very large underpredictions of experimental critical supersaturations by the bulk solution representation $\left(S S_{c}^{\sigma, b}<<S S_{c}^{\exp }\right)$. Thus, $\sigma, b$ does not appear to provide a satisfactory representation of the effects of surfactant properties on cloud droplet activation for the particles studied here.

In principle, the differences between $S S_{c}^{\exp }$ and predictions using either $\sigma, p$ or $\sigma_{w}$ might be explained by model 
sensitivity to uncertainties in various experimental parameters. Conditions where the effects of surfactant properties become significant for Köhler predictions and gauges for the applicability of $\sigma, p$ and $\sigma_{w}$, respectively, to particles comprising different surfactants should therefore be investigated more closely in future work. Establishing explicit gauges for the representation of surfactants in cloud droplet activation, for example given with respect to dry particle parameters $D_{p}$ and $W_{p, \text { SFT }}$, as well as surfactant molecular parameters like $M_{\mathrm{SFT}}$ and Szyskowski parameters $a$ and $b$, would be of great use for applications to atmospheric modeling. When the mixed particles comprise less than $50 \%$ by mass of surfactant, representations $\sigma, p$ and $\sigma_{w}$ give very similar predictions of critical supersaturations and both describe experimental values well. As a simple preliminary gauge, the $\sigma_{w}$ representation, which ignores surfactant properties altogether, thus appears to be a good first-order approximation for describing surfactant activation properties in these particles.

\subsection{Particle size-dependent effects}

It was seen in Sect. 5.2 (Figs. 2-5) that theoretical $\log S S_{c}-$ $\log D_{p}$ slopes are all close to the ideal value of $-3 / 2$ predicted from simple equilibrium Köhler theory (Seinfeld and Pandis, 2006). Thus, even for calculations with $\sigma, p$ that include effects of size-dependent surface-area-to-bulk-volume ratio for activating droplets, a significant variation of the resulting activation properties with dry particle size is not evident. On the other hand, experimental slopes are greater than $-3 / 2$ (more shallow) in all cases, and in particular for particles comprising FAS. With $\sigma, p$ and $\sigma_{w}, S S_{c}^{\exp }$ are both seen to be smaller than predicted values for the smaller $D_{p}$, and larger for the larger $D_{p}$. We have not been able to identify a single mechanism that would simultaneously explain both the overprediction of $S S_{c}^{\exp }$ for the smaller particles and the underprediction for the larger particles. Likely, a combination of a number of different mechanisms is in effect.

Size-dependent deviations of $S S_{c}^{\exp }$ from theoretical predictions may be caused by experimental conditions unaccounted for in our equilibrium Köhler model. In principle, any of the mechanisms mentioned in relation to model sensitivity above (uncertainty in surface tension parameterizations, FAS density, dry particle composition, size and shape, and solution effects like non-ideality and solute dissociation and limited bulk concentration, see also App. B) may also introduce size-dependent effects on activation. Furthermore, kinetic effects may influence the properties of generated particles with different sizes to different extents. For example, size-dependent changes in produced particle compositions from that of the solute in the atomizer solution may result, if organic evaporation from supersaturated droplets is enhanced from the larger surfaces of smaller droplets with smaller curvature radii, or if retention of residual water from insufficient drying is enhanced in larger droplets with greater bulk volumes.

Kinetic effects could also inhibit equilibrium droplet activation in the $\mathrm{CCN}$-counter. Properties of the activating solution droplets could be affected by limited diffusion of surfactant molecules to the droplet surface or slow dissolution of the dry particle components into the droplet phase. Test calculations using a cloud parcel model (H. Kokkola, personal communication, 2010) show that molecular diffusion processes within the aqueous droplets are an order of magnitude faster than characteristic activation time-scales for droplets in the $\mathrm{CCN}$-counter. It is, however, still conceivable that slow dissolution of dry particle components could kinetically inhibit droplet activation of preferentially the larger particles. In addition, film formation by surfactant molecules partitioned to the surface could affect the rate of condensation of water vapor to the droplet. Concentration-dependent (kinetics of) chemical reactions of the droplet solution components, possibly with impurities present in the system, could also influence droplet properties during activation. Currently, we do not have the means to estimate the magnitudes of these effects for predictions of droplet activation.

\subsection{Fatty acids salts vs. SDS}

Comparing our results for mixed particles comprising FAS and SDS, respectively, some differences should be noted. First, experimental errors depicted for particles comprising FAS are significantly greater than for SDS. Second, deviations of the $\log S S_{c}^{\exp }-\log D_{p}$ slopes from $-3 / 2$ are smaller for SDS particles than for FAS. In addition to the mechanisms mentioned in Sect. 5.4 above, the $\log S S_{c}^{\exp }-\log D_{p}$ slopes for FAS particles could therefore also be related to uncertainties in activation curve fitting. Uncertainties in dry particle surfactant mass-fraction would on the other hand be similar for FAS and SDS, and are therefore less likely to explain the observed differences. Significant $\log S S_{c}^{\exp }-\log D_{p}$ slope deviations were not observed for the pure FAS particles in our previous study (Prisle et al., 2008). The slope deviations in case of the mixed FAS- $\mathrm{NaCl}$ particles thus also seem less likely to be caused by uncertainties in FAS mass-density.

Third, the overprediction of $S S_{c}^{\text {exp }}$ by $\sigma, p$ for high $W_{p, \text { SFT }}$ is seen for FAS, but not for SDS. This suggests that observed $S S_{c}^{\sigma, p}>S S_{c}^{\exp }$ for FAS may at least partly be due to uncertainties in FAS properties (as opposed to failure of $\sigma, p$ to capture surfactant activation properties), in particular the dry mass densities and ternary surface tension parameterizations. These properties are well-known for SDS and future work should establish better constraints for FAS in order to improve evaluation of the model predictions using $\sigma, p$ against laboratory measurements. Molecular masses and surfactant strengths are comparable for SDS and the studied FAS. If this is also the case for water solubilities, vapor pressures, and particle shape when mixed with $\mathrm{NaCl}$, sensitivities of model predicted activation related to these properties should 
be similar for SDS and FAS. Uncertainties in these properties would then be less likely to cause the differences in the ability of $\sigma, p$ to predict $S S_{c}^{\exp }$ for FAS. It must be noted, however, that particles with $W_{p, \text { SDS }}>80 \%$ were not studied here. Activation properties for these particle compositions should be measured in future work to establish the predictions of $S S_{c}^{\sigma, p}$ for the highest mass fractions of SDS.

\section{Conclusions}

We have measured critical supersaturations for laboratorygenerated particles comprising the organic surfactants sodium octanoate, sodium decanoate, sodium dodecanoate, and sodium dodecyl sulfate, mixed with sodium chloride. Results were modeled from Köhler theory using three different representations of surfactant properties. A comprehensive thermodynamic account of surfactant properties, including the effects of surface partitioning and reduced surface tension in activating droplets generally describes experimental observations well. On the other hand, using reduced droplet surface tension while ignoring surfactant surface partitioning in all cases greatly underpredicts experimental critical supersaturations. This approach therefore does not provide an adequate representation of cloud droplet activation properties for the studied particle compositions. Disregarding surfactant partitioning and simply assuming the constant surface tension of pure water for the activating droplets overall describes observed activation well, but can also lead to significant underpredictions of experimental critical supersaturation values. For these particles, surfactant properties indeed seem to affect the ability to activate into cloud droplets. Still, for mixed particles comprising less than about $50 \%$ by mass of surfactant, the simple solute approach appears to be a good first-order approximation for representing surfactant properties in activating droplets. This entails a considerable simplification for model calculations of cloud droplet formation and properties.

\section{Appendix A}

\section{Simple partitioning example}

The effect of surfactant partitioning on the magnitude of both water activity and surface tension, resulting from a given overall solution composition, can be illustrated with the following simple example. We assume that spherical droplets of different diameters $(d[\mu \mathrm{m}])$ are created from the same binary surfactant aqueous solution with a fixed total surfactant molarity $\left(c^{T}\left[\mathrm{mmolL}^{-1}\right]\right)$. The total molar amount of surfactant in the droplet $\left(n^{T}[\mathrm{~mol}]\right)$ can be calculated from $c^{T}$ and the droplet volume $(V[\mathrm{~L}])$. We imagine the surface as an infinitely thin spherical shell with area $A\left[\mathrm{~m}^{2}\right]$. A fixed surfactant surface excess $\left(\Gamma\left[\mathrm{m}^{-2}\right]\right.$, the number area concentration of surfactant molecules in the surface phase) is as-
Table A1. Surfactant bulk molarities $\left(c^{B}\right)$, ratio of surfactant bulk and total $\left(c^{T}\right)$ molarities, and droplet surface tension, $\sigma=\sigma\left(c^{B}\right)$, for droplets of different diameters $(d)$ created from the same $c^{T}=$ $40 \mathrm{mmolL}^{-1}$ sodium decanoate $(\mathrm{C} 10 \mathrm{Na})$ solution. Surfactant surface excess is fixed to $\Gamma=10^{18} \mathrm{~m}^{-2}$ for all droplet sizes.

\begin{tabular}{ccccc}
\hline $\begin{array}{c}d \\
{[\mu \mathrm{m}]}\end{array}$ & $\begin{array}{c}A / V \\
{\left[\mu \mathrm{m}^{-1}\right]}\end{array}$ & $\begin{array}{c}c^{B} \\
{\left[\mathrm{mmol} \mathrm{L}^{-1}\right]}\end{array}$ & $c^{B} / c^{T}$ & $\begin{array}{c}\sigma \\
{\left[\mathrm{mN} \mathrm{m}^{-1}\right]}\end{array}$ \\
\hline 0.3 & 20 & 6.8 & 0.170 & 68 \\
0.5 & 12 & 20.1 & 0.502 & 61 \\
1 & 6 & 30.0 & 0.751 & 57 \\
10 & 0.6 & 39.0 & 0.975 & 54 \\
50 & 0.12 & 39.8 & 0.995 & 54 \\
$\infty$ & 0 & 40.0 & 1.000 & 54 \\
\hline
\end{tabular}

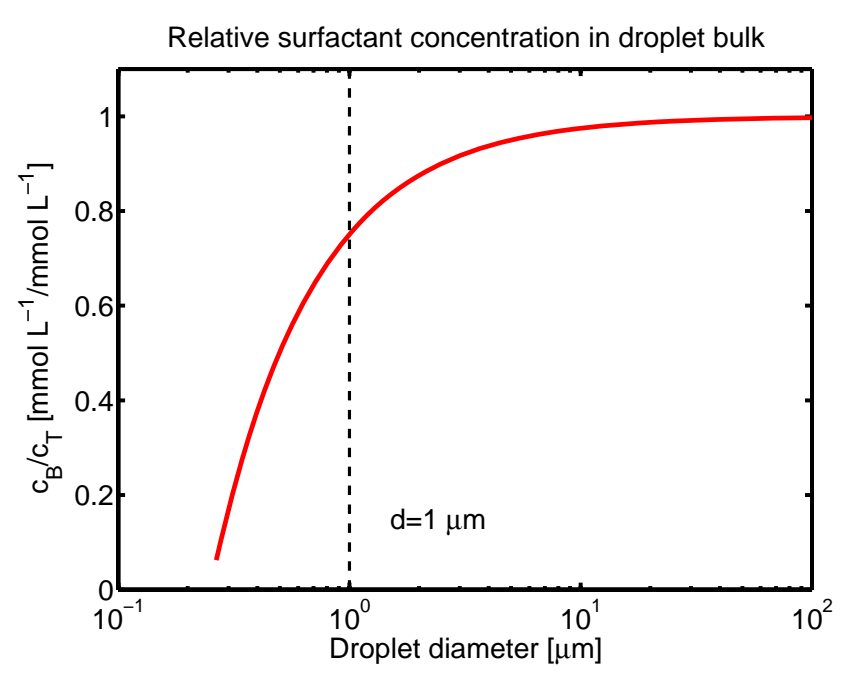

Fig. A1. Ratio of surfactant bulk $\left(c^{B}\right)$ and total $\left(c^{T}\right)$ molarities as a function of droplet diameter $(d)$. Droplets of all sizes have fixed total surfactant molarity $c^{T}=40 \mathrm{mmolL}^{-1}$ and surfactant surface excess $\Gamma=10^{18} \mathrm{~m}^{-2}$.

sumed for droplets of all sizes. The amount of surfactant in the surface $\left(n^{S}[\mathrm{~mol}]\right)$ is then calculated by simply scaling $\Gamma$ to the spherical droplet surface area, as $n^{S}=\Gamma A$. From this, the size-dependent surfactant bulk-phase concentration $\left(c^{B}\left[\mathrm{mmolL}^{-1}\right]\right)$ is $c^{B}(d)=c^{T}-6 \times 10^{9} \Gamma / N_{a} d$, where $N_{a}$ is Avogadro's number.

Representative values for surfactant surface excess and total molarity are taken from our previous study on singlecomponent fatty acid salt particles (Prisle et al., 2008), specifically as the values at the point of activation for droplets formed on $100 \mathrm{~nm}$ sodium decanoate $(\mathrm{C} 10 \mathrm{Na})$ particles, $\Gamma=$ $10^{18} \mathrm{~m}^{-2}$ and $c^{T}=40 \mathrm{mmolL}^{-1}$. Droplet surface tension is calculated from the surfactant bulk-phase concentration using the concentration-dependent parametrization $\sigma=\sigma\left(c^{B}\right)$ for binary sodium decanoate aqueous solutions given in Prisle et al. (2008). We ignore non-ideal interactions in 
(a) Density, $\rho$ : $40 \mathrm{~nm} \mathrm{C} 8 \mathrm{Na}+\mathrm{NaCl}$

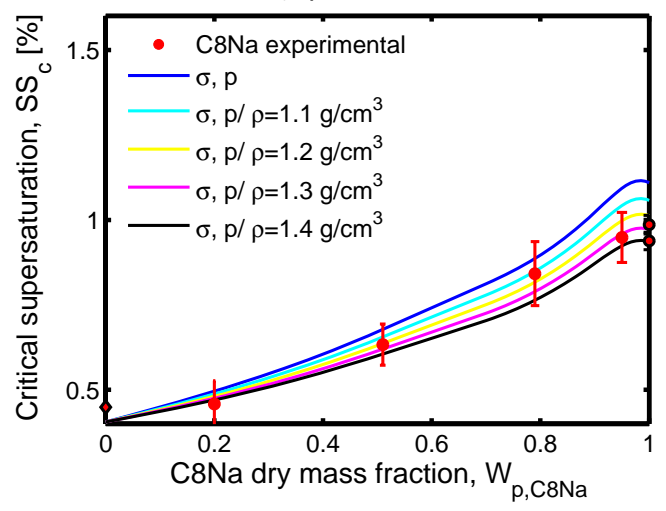

(c) Dissociation, $\delta: 40 \mathrm{~nm}$ C12Na $+\mathrm{NaCl}$

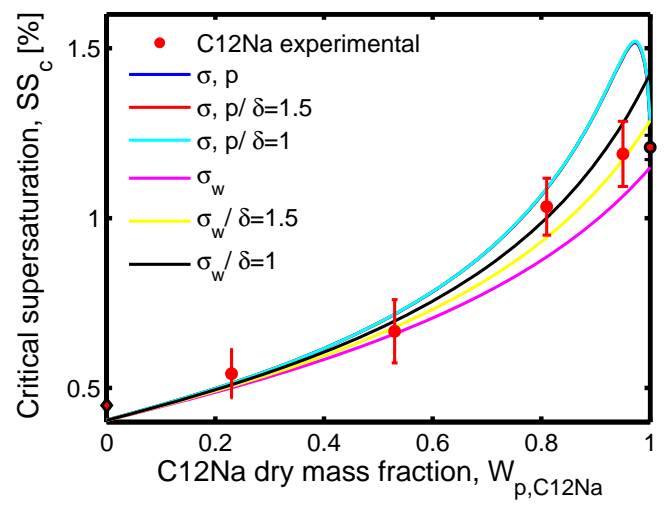

(b) Composition, shape: $40 \mathrm{~nm} \mathrm{C10Na}+\mathrm{NaCl}$

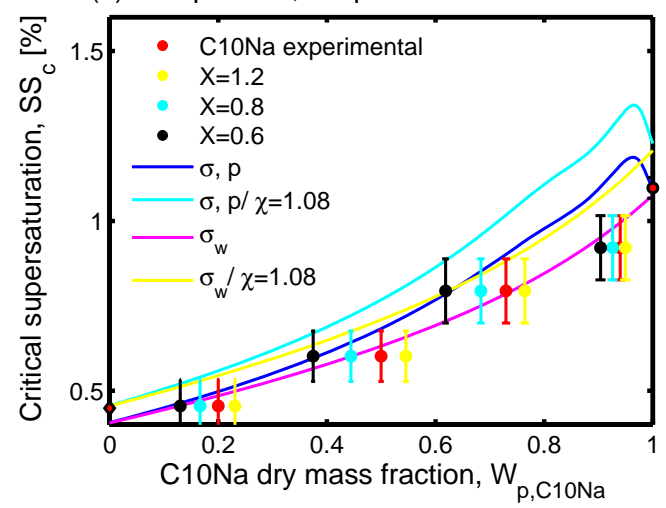

(d) Non-ideality, $\gamma: 40 \mathrm{~nm} \mathrm{C12Na}+\mathrm{NaCl}$

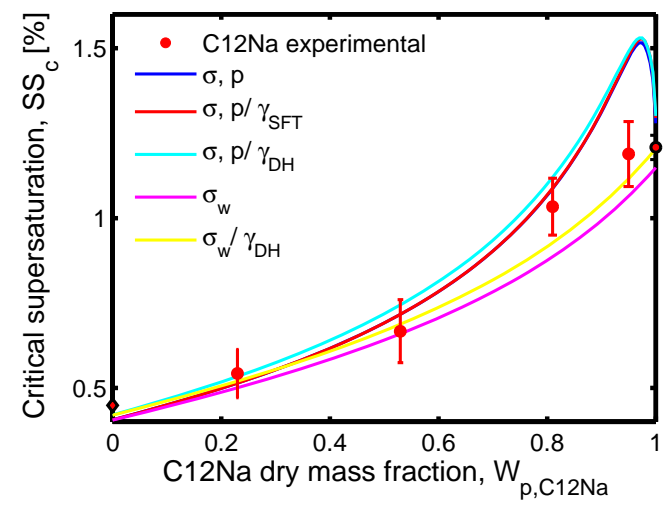

Fig. B1. Selected results of Köhler model sensitivity calculations, illustrating the effects for predicted critical supersaturations $\left(S S_{c}[\%]\right)$ as functions of total dry particle surfactant mass-fractions $\left(W_{p, \mathrm{SFT}}\right)$ of: $(\mathbf{a})$ FAS bulk mass-density $\rho_{\mathrm{FAS}}=1.1,1.2,1.3,1.4 \mathrm{gcm}{ }^{-3},(\mathbf{b}) \mathrm{dry}$ particle composition, in terms of decreasing total surfactant mass-fraction from the nominal value $\left(W_{p}, \mathrm{SFT}\right)$, and volume-equivalent diameter $\left(D_{p}^{e}\right),(\mathbf{c})$ surfactant dissociation factor $\delta_{\mathrm{SFT}}=1.0,1.5$, and $(\mathbf{d})$ droplet solution non-ideality, in terms of decreased organic activity $\left(\gamma_{\mathrm{SFT}}\right)$ and all droplet component activities predicted from Debye-Hückel theory $\left(\gamma_{\mathrm{DH}}\right)$. Results are shown for different surfactants and surfactant property representations. See individual Sects. B1-B4 for details.

the droplet solutions, such that droplet water activity $\left(a_{w}\right)$ is given by the equivalent water mole fraction $\left(x_{w}\right)$. Then, the ratio $c^{B} / c^{T}$ provides a measure of how much surfactant surface partitioning at a given droplet size $(d)$ diminishes the water activity suppression and surface tension reduction that can be achieved for the same total surfactant concentration.

Results of these simple calculations are presented in Table A1 and in Fig. A1. Surfactant surface partitioning in this case becomes important for sub-micron droplets $(d<1 \mu \mathrm{m})$. When the surfactant bulk-concentration decreases due to surface partitioning, both water activity and surface tension in the droplet are increased accordingly.

\section{Appendix B Model sensitivity}

The sensitivity of our Köhler model was tested to a number of the assumptions listed in Sect. 4.4, by making predictions for selected ranges of the corresponding parameter values. For particles comprising the fatty acid salts (FAS), model sensi- tivity was tested to uncertainty in the FAS bulk mass-density (Sect. B1). For both FAS and sodium dodecyl sulfate (SDS) particles, model sensitivities were furthermore tested to experimental conditions leading to variations in dry particle surfactant (SFT) mass-fractions and total amount of solute (Sect. B2), and to possible solution effects occurring within the activating droplets, in terms of surfactant dissociation (Sect. B3), non-ideal droplet component activities (Sect. B4), and limited surfactant concentration in the droplet bulk-phase (Sect. B5). Selected results of the sensitivity calculations for $40 \mathrm{~nm}$ dry particles are shown in Figs. B1 and B2. Due to the larger total droplet concentrations predicted at the point of activation, model sensitivity is generally greater for the smaller particles. Moreover, as noted in Sect. 5.2, some sizedependent effect may cause all model calculations to underpredict $S S_{c}^{\exp }$ for the larger particles comprising FAS, thus making the sensitivity analysis less representative in these cases. 
(a) Köhler curves: $40 \mathrm{~nm} 81 \% \mathrm{C} 12 \mathrm{Na}$

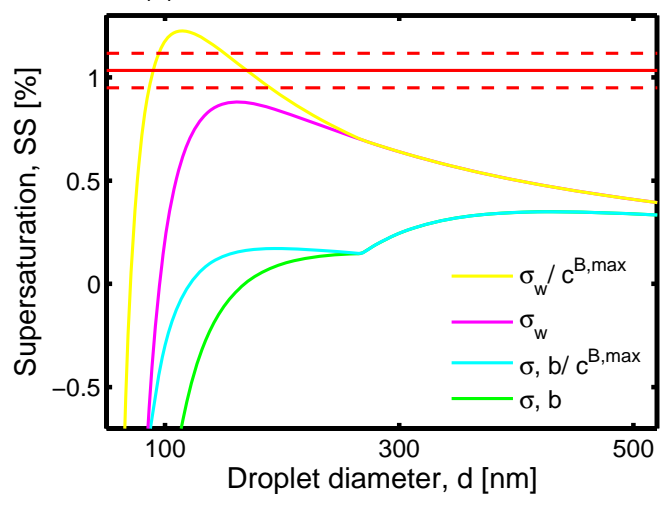

(c) $40 \mathrm{~nm} \mathrm{C12Na}+\mathrm{NaCl}$ particles

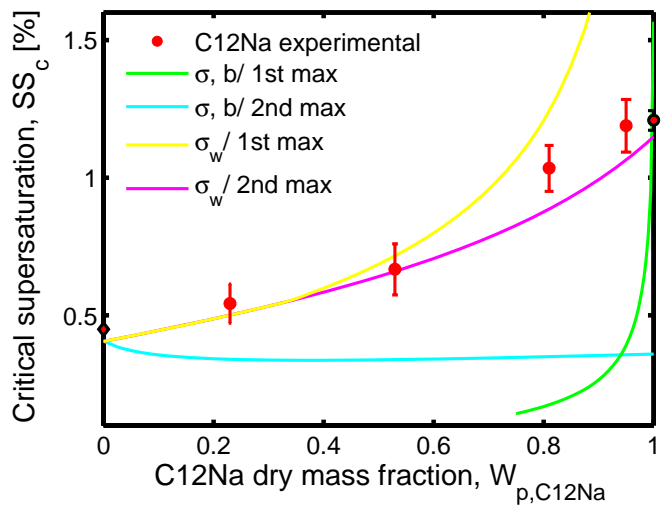

Fig. B2. Model predictions with surfactant representations $\sigma, b$ and $\sigma_{w}$, for dry sodium dodecanoate $(\mathrm{C} 12 \mathrm{Na})$ and $\mathrm{NaCl}$ particles of diameter $D_{p}=40 \mathrm{~nm}$, testing the sensitivity to limited C12Na concentration in the droplet bulk-phase $\left(c_{\mathrm{C} 12 \mathrm{Na}}^{B}\right)$ : (a) individual Köhler curves for particles comprising $81 \%$ by mass of $\mathrm{C} 12 \mathrm{Na}$, and (b) critical supersaturations $\left(S S_{C}[\%]\right)$, given by the predicted Köhler curve maxima, as functions of dry particle $\mathrm{C} 12 \mathrm{Na}$ mass-fraction $\left(W_{p, \mathrm{C} 12 \mathrm{Na}}\right)$. In panel (a), the experimental critical supersaturation with corresponding 95\%-confidence interval is depicted with the solid and stipulated red lines, respectively. See Sect. B5 for details.

\section{B1 Fatty acid salt densities}

Bulk mass-densities for the studied FAS were assumed to be unity $\left(\rho_{\text {FAS }}=1 \mathrm{gcm}^{-3}\right)$, whereas for SDS the density is $1.176 \mathrm{gcm}^{-3}$ (see Table 2). As FAS densities below unity are considered unlikely (Prisle et al., 2008), the sensitivity of model predictions was tested to $\rho_{\mathrm{FAS}}=$ $1.1,1.2,1.3$, and $1.4 \mathrm{gcm}^{-3}$, respectively. Larger surfactant density implies more solute is available within activating droplets formed on dry particles of a given size. This may yield greater reductions in both water activity and surface tension, leading to larger critical droplets with smaller predicted critical supersaturations $\left(S S_{c}\right)$.

Results of varying surfactant density are shown in Fig. B1 (a) for $40 \mathrm{~nm}$ mixed sodium octanoate $(\mathrm{C} 8 \mathrm{Na})$ and $\mathrm{NaCl}$ particles calculated with the $\sigma, p$ representation. A density of $\rho_{\mathrm{C} 8 \mathrm{Na}}=1.2 \mathrm{gcm}^{-3}$, very close to the corresponding value for SDS, can resolve a significant amount of the discrepancy between experiments and $\sigma, p$ model predictions. This is also seen for $40 \mathrm{~nm}$ particles with sodium dodecanoate $(\mathrm{C} 12 \mathrm{Na})$, whereas for sodium decanoate $(\mathrm{C} 10 \mathrm{Na})$ a density of $1.4 \mathrm{gcm}^{-3}$ is needed. For calculations with the $\sigma_{w}$ representation (not shown), larger FAS densities lead to increasing underpredictions of $S S_{c}^{\exp }$, compared to the unity base value.

\section{B2 Dry particle parameters}

The predicted total amounts of surfactant and $\mathrm{NaCl}$ solute in the droplets are affected by the assumptions regarding dry particle volume and composition. Dry particles selected in the DMA are assumed to be spherical with diameters equal to the electrical-mobility diameter mode. For non-spherical particles, a (size-dependent) shape factor $\chi>1$ would re- duce the volume-equivalent particle diameter (Hinds, 1999) according to

$D_{p}^{e}=\frac{D_{p}}{\chi}$

and thus the available amounts of both surfactant and $\mathrm{NaCl}$ solute in the droplets calculated from Eq. (2). Compositions of dry particles produced in the experiments are assumed to reflect the solute composition within the atomizer solutions from which the particles are generated. Actual particle compositions could potentially deviate from these nominal values due to several mechanisms. Surface partitioning upon atomization could either in- or decrease surfactant mass-fraction relative to $\mathrm{NaCl}$ in the initially produced aqueous aerosol and thereby the corresponding fraction in the dry aerosol particles $\left(W_{p, \mathrm{SFT}}\right)$. Organic evaporation from the increasingly supersaturated solution droplets upon drying or from the dried particles further down-stream in the aerosol flow would decrease $W_{p, \text { SFT }}$. If evaporation of the organic occurs after particle size-selection in the DMA, both dry particle size $\left(D_{p}\right)$ and $W_{p, \text { SFT }}$ are decreased.

Vapor pressure data for the dry and aqueous surfactant$\mathrm{NaCl}$ mixtures in question are to our knowledge not available in the literature. Since both organic and inorganic particle components are salts, neither are however expected to have appreciable solid vapor pressures at ambient conditions. Particle residence times in the production line after size selection are $\sim 0.2 \mathrm{~s}$ and, on similar time scales, evaporation was not observed from dried particles of the pure surfactants in our previous study (Prisle et al., 2008). It is therefore not believed to be significant in the present experiments either. Still, formation of molecular carboxylic acids from protonation within the aqueous droplet phase may lead to some evaporation. The fatty acids are stronger surfactants 
than their salts (Fainerman et al., 2002) and may thus be even more partitioned to the droplet surface. Due to the increased concentrations upon surface accumulation, evaporation could here be enhanced compared to the bulk phase. In addition, continuing evaporation from the droplet phase upon dilution of the gas phase with purified air may shift the surface partitioning and protonation equilibria according to Le Chatelier's principle. At the present, this effect however remains purely speculative.

The effect of dry particle composition on the ability of model calculations to predict experimental critical supersaturations $\left(S S_{c}^{\exp }\right)$ was tested by shifting $S S_{c}^{\exp }$ according to changes in effective surfactant dry particle mass-fraction $\left(W_{p, \mathrm{SFT}}^{\prime}\right)$ from the nominal value

$W_{p, \mathrm{SFT}}^{\prime}=\frac{m_{\mathrm{SFT}} X}{m_{\mathrm{SFT}} X+m_{\mathrm{NaCl}}}=\frac{W_{p, \mathrm{SFT}} X}{W_{p, \mathrm{SFT}} X+W_{p, \mathrm{NaCl}}}$

resulting from changes in surfactant mass by $X=1.2$ ( $W_{p, \mathrm{SFT}}^{\prime}$ increase) and $X=0.8$ and $0.6\left(W_{p, \mathrm{SFT}}^{\prime}\right.$ decrease). Results are shown in Fig. B1 (b) for 40nm mixed sodium decanoate $(\mathrm{C} 10 \mathrm{Na})$ and $\mathrm{NaCl}$ particles, and compared to calculations with $\sigma, p$ and $\sigma_{w}$. For the same particles, Fig. B1 (b) also shows the effect on critical supersaturations predicted by $\sigma, p$ and $\sigma_{w}$ of decreasing $D_{p}^{e}$ from $D_{p}$ according to a mobility shape-factor of $\chi=1.08$, as would be the case for cubic particles for example formed by pure $\mathrm{NaCl}$ (Hinds, 1999). Decreased $W_{p, \text { SFT }}^{\prime}$ from the nominal value can in many cases resolve the overpredictions of $S S_{c}^{\exp }$ by $\sigma, p$. Still, rather large decreases of the organic fraction are needed, for the case depicted in Fig. B1 (b) a factor of $X \sim 0.6$, and for very large nominal $W_{p, \mathrm{SFT}}$, differences between $\sigma, p$ and experiments in general cannot be resolved. On the other hand, $W_{p, \mathrm{SFT}}^{\prime}>W_{p, \mathrm{SFT}}$, as well as a particle mobility shape-factor $\chi>1$, can in some cases resolve the underpredictions of $S S_{c}^{\exp }$ by $\sigma_{w}$. For both partitioning and organic evaporation mechanisms, the rate and thus final extent of change in surfactant dry particle mass-fraction from $W_{p, \mathrm{SFT}}$ during particle production could in addition be both mass fraction and size dependent.

\section{B3 Surfactant dissociation}

The studied surfactants are organic ionic electrolytes and assumed to be fully dissociated in the droplet bulk-phase, according to a dissociation factor $\delta_{\mathrm{SFT}}=2$. The effect on model predictions of incomplete surfactant dissociation was tested by applying $\delta_{\mathrm{SFT}}=1.5$ (half dissociated) and 1 (completely undissociated). With $\sigma, p$, calculations were made by evaluating the partitioning equilibrium as usual, and subsequently applying the relevant $\delta_{\text {SFT }}$ to the surfactant solute remaining in the droplet bulk-phase. Organic dissociation thus affects the water activity, but not the surface tension at a given droplet size. As a result, $\delta_{\mathrm{SFT}}<2$ will yield a smaller Raoult effect and in turn a smaller critical droplet, with a corresponding larger Kelvin term and a larger predicted $S S_{c}$.
Model sensitivity to surfactant dissociation is shown in Fig. B1 (c) for 40nm mixed sodium dodecanoate (C12Na) and $\mathrm{NaCl}$ particles, calculated with $\sigma, p$ and $\sigma_{w}$. The value of $\delta_{\mathrm{SFT}}$ has practically no influence on activation properties calculated with $\sigma, p$, due to very low surfactant bulk-phase concentrations predicted when surface partitioning is accounted for. With $\sigma_{w}$, on the other hand, there are differences in model predicted activation for the different surfactant dissociation factors applied. In the case of $40 \mathrm{~nm}$ mixed C12Na$\mathrm{NaCl}$ particles, $1<\delta_{\mathrm{SFT}}<1.5$ could in principle resolve the differences between $S S_{c}^{\text {exp }}$ and $S S_{c}^{\sigma_{w}}$. Bulk solution dissociation constants would be required to evaluate if such low dissociation states for the organic electrolyte provide an equally thermodynamically consistent mechanism for the observed activation as surface partitioning.

\section{B4 Droplet component activities}

Model calculations assume droplet solution ideality in terms of unit bulk-phase activity coefficients $\left(\gamma_{i}^{B}=1\right)$ for all components. Experimental mean-ionic molality-based activity coefficients $\left(\gamma_{ \pm}\right)$for C10Na are given by DeLisi et al. (1981). Debye-Hückel theory (Debye and Hückel, 1923; Clegg et al., 1992) gives excellent agreement with these values up to the critical micelle concentration $(\mathrm{cmc})$.

Model sensitivity to the ideality assumption was tested by two different approaches. First, ideality is assumed valid for water while applying various concentration-dependent organic and salt mean activity coefficients $\left(\gamma_{\mathrm{SFT}}\right)$. Second, all droplet component concentration-dependent bulk-phase activity coefficients are predicted from Debye-Hückel theory $\left(\gamma_{\mathrm{DH}}\right)$. When surface partitioning is ignored, either increasing water activity or decreasing ionic activities will act to decrease the Raoult effect and thus increase predicted $S S_{c}$. Including partitioning, mean-ionic activity coefficients below unity are expected to decrease the extent of surfactant surface partitioning. The combined effects on surface tension, Raoult term and ultimately on droplet activation are thus not readily anticipated.

Predicted effects of varying droplet component bulk-phase activities are shown in Fig. B1 (d) for 40nm mixed sodium dodecanoate $(\mathrm{C} 12 \mathrm{Na})$ and $\mathrm{NaCl}$ particles. For the first approach, calculations with $\sigma_{w}$ are identical to the base case, and only results for $\sigma, p$ are shown. For the second approach, calculations are shown for both $\sigma, p$ and $\sigma_{w}$. Considering only organic solute non-ideal activities, the effect is small and within experimental error. Only when non-ideal water activity $\left(a_{w}\right)$ is also included, by using Debye-Hückel theory for all droplet solution components, is a discernable effect achieved. Predicted $S S_{c}$ values increase as $a_{w}>x_{w}$ and results for $\sigma, p$ consequently describe experiments less well. On the other hand, the effect is unable to resolve the underpredictions of $S S_{c}^{\exp }$ by $\sigma_{w}$. This is seen over the entire range of dry particle sizes. 


\section{B5 Limited surfactant bulk-phase concentration}

Full water solubility within the activating droplets is assumed for both surfactant and $\mathrm{NaCl}$ solutes, despite that limited solubility of the organic surfactants in bulk aqueous solutions may be expected from the carbon chain length, and is indeed observed upon preparation of the atomizer solutions. Concentrations of free dissolved surfactant molecules in the droplet bulk-phase are furthermore assumed not to be limited by formation of micelles, even as the cmc values of the corresponding ternary bulk aqueous solutions are exceeded. If the surfactant concentration in the droplet bulk-phase was limited to that of a saturated macroscopic solution, or to the macroscopic ternary solution $\mathrm{cmc}$, sufficiently small values of these concentrations could inhibit droplet activation by a mechanism analogous to that described by Shulman et al. (1996). In model predictions, limited surfactant bulk-phase concentration imposes a maximum on the attainable water activity and surface tension reduction. This can affect the shape of the predicted Köhler curve for the droplet and possibly introduce a second local maximum, both of which may in turn affect the predicted $S S_{c}$.

To our knowledge, neither organic solubilities, nor cmc values, for the relevant ternary SFT-NaCl solutions are available in the literature. The effect of limited surfactant bulk-phase concentration for model predictions was therefore tested by imposing a maximum on the evaluated bulkphase concentration of dissolved surfactant in the activating droplets $\left(c_{\mathrm{SFT}}^{B} \leq c_{\mathrm{SFT}}^{B, \max }\right)$. This maximum concentration value was in each case obtained, such that the droplet solution surface tension, as determined from the ternary surface tension parameterizations, was kept above the respective minimum values observed in measurements for bulk aqueous solutions of each surfactant (see Sect. 4.3). In cases where the total amount of surfactant leads to concentrations higher than $c_{\mathrm{SFT}}^{B, \max }$, additional surfactant solute is thus considered as a solid phase. Due to the presence of the water-soluble inorganic salt, droplet activation controlled by the onset of particle deliquescence, as described by Bilde and Svenningsson (2004), is not expected for the mixed particles studied in the present experiments. Therefore, the effect of this mechanism for model predictions was not considered.

In calculations with $\sigma, p$, imposed $c_{\mathrm{SFT}}^{B, \max }$ values are never exceeded at the point of droplet activation, for any of the studied surfactants and over the full ranges of dry particle surfactant mass-fractions. Predicted $S S_{c}{ }^{\sigma, p}$ are thus unaffected by this mechanism. Calculations are therefore shown in Fig. B2 with $\sigma, b$ and $\sigma_{w}$, for $40 \mathrm{~nm}$ mixed sodium dodecanoate $(\mathrm{C} 12 \mathrm{Na})$ and $\mathrm{NaCl}$ particles. The left panel (a) in Fig. B2 shows predicted Köhler curves for particles with $W_{p, \mathrm{C} 12 \mathrm{Na}}=81 \%$, and the rigth panel (b) shows the (possibly dual) Köhler curve maxima predicted over the full range of

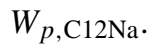

The shapes of the calculated Köhler curves are generally affected by limiting $c_{\mathrm{SFT}}^{B}$, in both $\sigma, b$ and $\sigma_{w}$ models. At low $W_{p, \text { SFT }}$, predicted $S S_{c}$ are nevertheless unaffected, whereas the value at the critical point of droplet activation is indeed increased at higher $W_{p, \mathrm{SFT}}$. For $\sigma, b$, limited surfactant bulkphase concentration is still incapable of resolving the underpredictions of $S S_{c}^{\exp }$. For $\sigma_{w}$, this mechanism can in some cases lead to better agreement with experiments, but more often, and in particular for the highest $W_{p, \mathrm{SFT}}$, predicted $S S_{c}{ }^{{ }}{ }_{w}$ are raised far above experimental values. It may also seem somewhat counter-intuitive to effectively account for organic precipitation (or micelle formation) within droplets where surface tension reduction and surface partitioning are not considered. Limited $c_{\mathrm{SFT}}^{B}$ is therefore not considered a likely mechanism for explaining the activation behavior observed in our experiments. As a consequence, we also do not find it necessary to explicitly account for micelle formation within the activating droplets, to achieve a thermodynamically consistent representation of surfactant properties in our model calculations.

In several previous studies, observed activation properties for organic compounds with limited solubility in bulk aqueous solutions indicate they are fully dissolved in the droplet solutions, including the pure organic surfactants studied here (Sorjamaa et al., 2004; Prisle et al., 2008). Mechanisms such as curvature-enhanced solubility of the sub-micrometer sized dry particle mixtures (Padro and Nenes, 2007), retention of various amounts of residual water within the dried particles (Hartz et al., 2006), and the presence of small amounts of soluble impurities (Bilde and Svenningsson, 2004), have been proposed to explain this observation. The latter effect may be further facilitated due to depression of the deliquescence relative humidity by the organic (Prisle et al., 2010a). Surface partitioning of the organic can also explain this observation, by decreasing the amount of dissolved solute remaining in the droplet bulk below the macroscopic solution solubility limit. This is exactly what is seen in the present sensitivity calculations using $\sigma, p$.

Acknowledgements. The authors gratefully acknowledge the funding received for this work from EUCAARI (European Integrated project on Aerosol Cloud Climate and Air Quality interactions) No. 036833-2, the Danish Natural Science Research Council (Copenhagen Center for Atmospheric Research), the Academy of Finland Center of Excellence program (project number 1118615), the Carlsberg Foundation (grant 2009_01_0366), and ACCENT Access to infrastructures. We thank Matthew S. Johnson and Harri Kokkola for valuable comments.

Edited by: J. Thornton 


\section{References}

Asa-Awuku, A. and Sullivan, A.: Investigation of molar volume and surfactant characteristics of water-soluble organic compounds in biomass burning aerosol, Atmos. Chem. Phys., 8, 799-812, doi:10.5194/acp-8-799-2008, 2008.

Bianco, H. and Marmur, A.: The Dependence of the Surface Tension of Surfactant Solutions on Drop Size, J. Coll. Interf. Sci., 151, 517-522, 1992.

Bilde, M. and Svenningsson, B.: CCN Activation of Slightly Soluble Organics: The Importance of Small Amounts of Inorganic Salt and Particle Phase, Tellus, 56B, 128-134, 2004.

Campbell, A. N. and Lakshminarayanan, G. R.: Conductances and Surface Tensions of Aqueous Solutions of Sodium Decanoate Sodium Laurate and Sodium Myristate at $25^{\circ} \mathrm{C}$ and $35^{\circ} \mathrm{C}$, Canad. J. Chem., 43, 1729-1737, 1965.

Cheng, Y., Li, S.-M., Leithead, A., Brickell, P. C., and Leaitch, W. R.: Characterizations of cis-pinonic acid and n-fatty acids on fine aerosols in the Lower Fraser Valley during Pacific 2001 Air Quality Study, Atmos. Environ., 38, 5789-5800, 2004.

Clegg, S. L., Pitzer, K. S., and Brimblecombe, P.: Thermodynamics of Multicomponent, Miscible, Ionic Solutions. 2. Mixtures Including Unsymmetrical Electrolytes, J. Phys. Chem., 96, 94709479, 1992.

Corrin, M. L. and Harkins, W. D.: The Effect of Salts on the Critical Concentration for the Formation of Micelles in Colloidal Electrolytes, J. Amer. Chem. Soc., 69, 683-688, 1947.

Debye, P. and Hückel, E.: The theory of electrolytes. I. Lowering of freezing point and related phenomena, Physikalische Zeitschrift, 24, 185-206, 1923.

DeLisi, R., Perron, G., Paquette, J., and Desnoyers, J. E.: Thermodynamics of micellar systems: activity and entropy of sodium decanoate and n-alkylamine hydrobromides in water, Can. J. Chem., 59, 1865-1871, 1981.

Dinar, E. and Taraniuk, I.: Cloud Condensation Nuclei properties of model and atmospheric HULIS, Atmos. Chem. Phys., 6, 24652481, doi:10.5194/acp-6-2465-2006, 2006.

Facchini, M., Mircea, M., Fuzzi, S., and Charlson, R.: Cloud Albedo Enhancement by Surface-Active Organic Solutes in Growing Droplets, Nature, 401, 257-259, 1999.

Facchini, M., Decesari, S., Mircea, M., Fuzzi, S., and Loglio, G.: Surface Tension of Atmospheric Wet Aerosol and Cloud/Fog Droplets in Relation to their Organic Carbon Content and Chemical Composition, Atmos. Environ., 34, 4853-4857, 2000.

Fainerman, V. B., Miller, R., and Möhwald, H.: General Relationships of the Adsorption Behavior of Surfactants at the Water/Air Interface, J. Phys. Chem. B, 106, 809-819, 2002.

Gibbs, J., Bumstead, H., Longley, W., and Name, R. V.: The Collected Works of J. Willard Gibbs, Longmans, Green and Co., 1928.

Hartz, K., Tischuk, J., Chan, M., Chan, C., Donahue, N., and Pandis, S.: Cloud Condensation Nuclei Activation of Limited Solubility Organic Aerosol, Atmos. Environ., 40, 605-617, 2006.

Hartz, K. E. H., Rosenørn, T., Ferchak, S. R., Raymond, T. M., Bilde, M., Donahue, N. M., and Pandis, S. N.: Cloud Condensation Nuclei Activation of Monoterpene and Sesquiterpene Secondary Organic Aerosol, J. Geophys. Res., 110, D14208, 2005.

Hinds, W.: Aerosol Technology: Properties, Behavior, and Measurement of Airborne Particles, John Wiley \& Sons, Inc., 2nd edn., 1999.
IPCC: Climate Change 2007, The Physical Science Basis, Contribution of Working Group I to the Fourth Assessment Report of the Intergovernmental Panel on Climate Change, Cambridge University Press, 2007.

Kiss, G., Tombácz, E., and Hansson, H.-C.: Surface Tension Effects of Humic-Like Substances in the Aqueous Extract of Tropospheric Fine Aerosol, J. Atmos. Chem., 50, 279-294, 2005.

Köhler, H.: The Nucleus in and the Growth of Hygroscopic Droplets, Transactions of the Faraday Society, 32, 1152-1161, 1936.

Laaksonen, A.: The Composition Size Dependence of Aerosols Created by Dispersion of Surfactant Solutions, J. Coll. Interf. Sci., 159, 517-519, 1993.

Li, Z., Williams, A., and Rood, M.: Influence of Soluble Surfactant Properties on the Activation of Aerosol Particles Containing Inorganic Solute, J. Atmos. Sci., 55, 1859-1866, 1998.

Lin, B., McCormick, A. V., Davis, H. T., and Strey, R.: Solubility of sodium soaps in aqueous salt solutions, J. Coll. Interf. Sci., 291, 543-549, 2005.

Matijevic, E. and Pethica, B. A.: The properties of ionized monolayers, Part 1. Sodium dodecyl sulphate at the air/water interface, Trans. Faraday Soc., 54, 1383-1389, 1958.

Mochida, M., Kitamori, Y., Kawamura, K., Nojiri, Y., and Suzuki, K.: Fatty acids in the marine atmosphere: Factors governing their concentrations and evaluation of organic films on seasalt particles, J. Geophys. Res., 107, D17S4325, doi:10.1029/ 2001JD001278, 2002.

Mochida, M., Kawamura, K., Umemoto, N., Kobayashi, M., Matsunaga, S., Lim, H.-J., Turpin, B., Bates, T., and Simoneit, B.: Spatial distributions of oxygenated organic compounds (dicarboxylic acids, fatty acids, and levoglucosan) in marine aerosols over the western Pacific and off the coast of East Asia: Continental outflow of organic aerosols during the ACE-Asia campaign, J. Geophys. Res., 108, D23S8638, doi:10.1029/2002JD003249, 2003.

Murphy, D. M., Cziczo, D. J., Froyd, K. D., Hudson, P. K., Matthew, B. M., Middlebrook, M., Peltier, R. E., Sullivan, A., Thomson, D. S., and Weber, R. J.: Single-particle mass spectrometry of tropospheric aerosol particles, J. Geophys. Res., 111, D23S32, doi:10.1029/2006JD007340, 2006.

O’Dowd, C. D., Facchini, M. C., Cavalli, F., Ceburnis, D., Mircea, M., Decesari, S., Fuzzi, S., Yoon, Y. J., and Putaud, J.-P.: Biogenically driven organic contribution to marine aerosol, Nature, 431, 676-680, 2004.

Oros, D. and Simoneit, B.: Identification and emission rates of molecular tracers in coal smoke particulate matter, Fuel, 79, 515536, 2000.

Padro, L. and Nenes, A.: Cloud droplet activation: solubility revisited, Atmos. Chem. Phys. Discuss., 7, 2325-2355, doi:10.5194/acpd-7-2325-2007, 2007.

Prisle, N. L.: Cloud Condensation Nuclei Properties of Organic Aerosol Particles: Effects of Acid Dissociation and Surfactant Partitioning, M.Sc. Thesis, Department of Chemistry, Faculty of Science, University of Copenhagen, 2006.

Prisle, N. L., Raatikainen, T., Sorjamaa, R., Svenningsson, B., Laaksonen, A., and Bilde, M.: Surfactant partitioning in cloud droplet activation: a study of C8, C10, C12 and C14 normal fatty acid sodium salts, Tellus, 60B, 416-431, doi:10.1111/j. 1600-0889.2008.00352.x, 2008. 
Prisle, N. L., Engelhart, G. J., Bilde, M., and Donahue, N. M.: Humidity Influence on Gas-Particle Phase Partitioning of $\alpha$ Pinene $+\mathrm{O}_{3}$ Secondary Organic Aerosol, Geophys. Res. Lett., 37, L01802, doi:10.1029/2009GL041402, 2010a.

Prisle, N. L., Koskinen, J., Vanhanen, J., Bilde, M., Laaksonen, A., Virtanen, A., Lihavainen, H., and Hyvärinen, A.-P.: Surface tensions of ternary aqueous mixed organic surfactant and inorganic salt solutions measured with four different experimental methods, in preparation, 2010b.

Rehfeld, S. J.: Adsorption of Sodium Dodecyl Sulfate at Various Hydrocarbon-Water Interfaces, The Journal of Physical Chemistry, 71, 738-745, 1967.

Rood, M. J. and Williams, A. L.: Reply, J. Atmos. Sci., 58, 14681473, 2001.

Ruehl, C. R., Chuang, P. Y., and Nenes, A.: Aerosol hygroscopicity at high (99 to 100\%) relative humidities, Atmos. Chem. Phys., 10, 1329-1344, doi:10.5194/acp-10-1329-2010, 2010.

Seidl, W. and Hanel, G.: Surface-Active Substances on Rainwater and Atmospheric Particles, Pure Appl. Geophys., 121, 10771093, 1983.

Seinfeld, J. H. and Pandis, S. N.: Atmos. Chem. Phys. -From Air Pollution to Climate Change, John Wiley and Sons, Inc., second edn., 2006.

Shulman, M., Jacobson, M., Charlson, R., Synovec, R., and Young, T.: Dissolution Behavior and Surface Tension Effects of Organic Compounds in Nucleating Cloud Droplets, Geophys. Res. Lett., 23, 277-280, 1996.

Snider, J. R., Petters, M. D., Wechsler, P., and Liu, P. S. K.: Supersaturation in the Wyoming CCN Instrument, J. Atmos. Ocean. Tech., 23, 1323-1339, 2006.
Sorjamaa, R., Svenningsson, B., Raatikainen, T., Henning, S., Bilde, M., and Laaksonen, A.: The Role of Surfactants in Köhler Theory Reconsidered, Atmos. Chem. Phys., 4, 2107 2117, doi:10.5194/acp-4-2107-2004, 2004.

Svenningsson, B., Rissler, J., Swietlicki, E., Mircea, M., Bilde, M., Facchini, M. C., Decesari, S., Fuzzi, S., Zhou, J., Mønster, J., and Rosenørn, T.: Hygroscopic growth and critical supersaturations for mixed aerosol particles of inorganic and organic compounds of atmospheric relevance, Atmos. Chem. Phys., 6, 1937-1952, doi:10.5194/acp-6-1937-2006, 2006.

Szyskowski, B. V.: Experimentelle studien über kapillare eigenschaften der wässerigen lösungen von fettsauren, Zeitschrift für Physikalische Chemie, 64, 385-414, 1908.

Tuckermann, R.: Surface tension of aqueous solutions of watersoluble organic and inorganic compounds, Atmos. Environ., 41, 6265-6275, 2007.

Vanhanen, J., Hyvärinen, A.-P., Anttila, T., Raatikainen, T., Viisanen, Y., and Lihavainen, H.: Ternary solution of sodium chloride, succinic acid and water; surface tension and its influence on cloud droplet activation, Atmos. Chem. Phys., 8, 4595-4604, doi:10.5194/acp-8-4595-2008, 2008.

Yassaa, N., Meklati, B. Y., Cecinato, A., and Marino, F.: Particulate n-alkanes, n-alkanoic acids and polycyclic aromatic hydrocarbons in the atmosphere of Algiers City Area, Atmos. Environ., 35, 1843-1851, 2001. 